\title{
Characterization of Outer Membrane Vesicles from Fusobacterium nucleatum
}

\author{
Raafat Munshi* \\ King Abdulaziz University Hospital, Jeddah, Saudi Arabia
}

\begin{abstract}
Article Type: Article
Article Citation: Raafat Munshi. Characterization of outer membrane vesicles from Fusobacterium nucleatum Indian Journal of Science and Technology. 2020; 13(02), 161-192. D0l: 10.17485/ijst/2020/ v013i02/148492
\end{abstract}

Received date: 0 ctober 30, 2019

Accepted date: November 13, 2019

*Author for correspondence: Raafat Munshi - raafat.munshi@ gmail.com 9 King Abdulaziz University Hospital, Jeddah, Saudi Arabia

\begin{abstract}
Background/objectives: Fusobacterium nucleatum is an oral pathogen and is associated with the development of colorectal cancer (CRC). This study is to evaluate the ability of outer membrane vesicles (OMV) from F. nucleatum to modulate cellular responses in colonic cells. Methodology: Here we show that infection of colonic epithelial cellswith F.nucleatum and its OMV induce pro-inflammatory chemokine and cytokine production and promote an EMT-like pheno- and genotypes in vitro as demonstrated by suppression of E-cadherin and up-regulation of several mesenchymal markers. $F$. nucleatum and its OMV modulate the barrier function of intestinal monolayers, a process likely related to their demonstrated ability to degrade E-cadherin and suppress its expression. Findings: Analysis of the OMV proteome by mass spectrometry demonstrates that they harbor the known virulence factors that appear to be enriched with proteolytic activity. Novelty/contribution: Taken together, these data indicate that F. nucleatum OMV have the potential to contribute to disease progression in the context of CRC.
\end{abstract}

Keywords: Outer Membrane Vesicles, Fusobacterium nucleatum, Colorectal Cancer, Protease.

\section{Introduction}

In colorectal cancer (CRC), mutations in the APC/Wnt pathway in colonic epithelial stem cells lead to the formation of adenomatous lesions [1]. Current evidence indicates a role for the microbiota in CRC with specific species/genera and polymicrobial signatures associated with CRC adenomas and tumors [2-4]. Others have proposed a role for concomitant reduction of the anti-inflammatory butyrate-producing commensals (e.g., Roseburia, Lachnospiraceae) in the pathogenesis of CRC [3].

Consistent demonstration, however, of Fusobacterium nucleatum enrichment at colonic adenoma and tumor sites [5-10] has revealed that CRC patients with low abundance of $F$. nucleatum have prolonged survival compared to those with moderate to high abundance $[9,11]$. 
Coupled with its ability to evade the immune response by inhibiting NK cell cytotoxicity and tumor killing [12], this microbe is now being considered as a marker for CRC [13]. F. nucleatum adheres to and invades epithelial cells via the adhesin FadA [14] which engages with host E-cadherin resulting in nuclear translocation of $\beta$-catenin and activation of the Wnt pathway $[6,14]$. Pre-clinical studies show that F. nucleatum promotes colonic tumorigenesis. However, as F. nucleatum is considered a "bridging" biofilm-promoting organism in the oral cavity, disease progression may be influenced by mechanisms shared between bacterial species rather than just F. nucleatum [15].

With regard to pathogen-host interactions, we were interested to evaluate the role of F. nucleatum outer membrane vesicles (OMV) as potential modulators of host cellular responses as OMV can mimic the activities of pathogenic and non-pathogenic parental bacteria. OMVs are closed proteo-liposomes composed of LPS, lipids, lipoproteins/ peptides, porins/receptors, adhesins, and peptidoglycan. Functions attributed to OMVs include quorum sensing, horizontal transfer of virulence factors, co-aggregation, and biofilm formation in addition to having significant roles in disease.

Here we report that F. nucleatum OMV induce colonic epithelial cell proliferation; the release of pro-inflammatory and immune-regulatory cytokines; degrade E-cadherin and downregulate $\mathrm{CDH} 1$; disrupt barrier integrity of epithelial monolayers; initiate a proinflammatory milieu and induce morphological changes consistent with a mesenchymal phenotype/genotype. Taken together, these data suggest that F. nucleatum OMV are potent modulators of colonic epithelial cell function and may contribute to colonic pathology both at the site of colonization and distally.

\section{Materials and Methods}

\subsection{Bacterial Strains, Cell Lines, and Culture Conditions}

Fusobacterium nucleatum nucleatum (ATCC 25586), and the subspecies polymorphum (ATCC 10953) and vincentii (ATCC 49256) were purchased from the ATCC culture collection (ATCC, LGC, UK). All strains were grown at $37^{\circ} \mathrm{C}$ under anaerobic conditions using the AnaeroGen atmosphere generating system (ThermoScientific). Fusobacteria were thawed from frozen stock (BHI containing 50\% (v/v) glycerol) and grown on Columbia blood agar plates (Columbia agar base, Oxoid) supplemented with 7\% (v/v) defibrinated horse blood. For broth culture, Fusobacteria were grown in brain heart infusion broth which was pre-reduced for at least $24 \mathrm{~h}$ under anaerobic conditions before use. Different preparations of the bacterium were routinely Gram stained (Sigma) and observed under oil immersion $(100 \times)$ to ensure purity and to check morphology and integrity. The number of bacteria was quantified as described [16].

Colonic cancer cell lines were cultured in MEM supplemented with l-glutamine (Caco-2: ATCC HTP-37), Dulbecco's MEM/Hams F13 medium (T84: ATCC CCL-248) or RPMI (SW 480 and 620: ATCC CCL-228 and -227, respectively), LoVo (ATCC CCL229)) containing $10 \%(\mathrm{v} / \mathrm{v})$ foetal calf serum, penicillin $(100 \mathrm{U} / \mathrm{ml})$, and streptomycin $(100 \mu \mathrm{g} / \mathrm{ml})$. SW480 cells are a primary adenocarcinoma, non-metastatic, cell line and its 
lymph node metastasis equivalent [17]. T84, Caco-2, and LoVo cells are adherent human epithelial colon carcinoma cell lines which form polarized/differentiated monolayers on semi-permeable supports in vitro.

\subsection{Outer Membrane Vesicle Isolation and Proteomic Composition}

OMV were purified from broth cultures of Fusobacteria species essentially as described previously [18]. The bacteria were cultured $(10 \times 50 \mathrm{ml})$ for $48-72 \mathrm{~h}$ prior to OMV recovery. OMV were examined by transmission electron microscopy to determine purity and size heterogeneity. The OMVs were mounted onto carbon-colloidal-coated mesh grids and let settle for $60 \mathrm{~s}$. Residual non-adherent OMV were removed using filter paper wicks. The samples were left to air dry and stained using aqueous uranyl acetate $(1 \%, \mathrm{v} / \mathrm{v})$.

Purified OMV were subjected to SDS-PAGE and the resulting Colloidal Coomassie G-250 stained gel was cut into 10 pieces prior to in-gel digestion, using a ProGest Investigator in-gel digestion robot (Genomic Solutions, Ann Arbor, MI) using standard protocols at the BMS Mass Spectroscopy facility, University of St Andrews.

\subsection{Cell Proliferation}

Epithelial cells were seeded in 96 -well plates at $2 \times 104$ cells/well. Cells were either left untreated or stimulated with F. nucleatum (MOI: 0-500:1) or different amounts of OMV $(0-50 \mu \mathrm{g} / \mathrm{ml})$. Quadruplicate assays were undertaken with an additional well used to determine cell viability using the Trypan blue exclusion assay. After selected time points Cell Titre One reagent (Promega) was added and the absorbance $(490 \mathrm{~nm})$ read using Wallac Victor2 plate reader.

\subsection{Trans-epithelial Electrical Resistance (TEER)}

Caco-2 or T-84 colonic epithelial cells were seeded in 12-well $0.4 \mu \mathrm{m} 6.5 \mathrm{~mm}$ PET membrane inserts (uncoated polyethylene terephthalate plastic trace-etched membranes, Falcon, Beckton Dickinson) at $4-5 \times 105$ cells $/ \mathrm{ml}$. The cells were fed both apically and basally every $24-48 \mathrm{~h}$ and cultured in a humidified incubator at $37{ }^{\circ} \mathrm{C}, 5 \% \mathrm{CO}$. The TEER was measured using an EVOM epithelial voltammeter apparatus (World Precision Instruments). Typically, fully polarized and differentiated monolayers took 10-14 days to form after which time the monolayers were exposed to bacteria/OMV and the resistance monitored over time. Triplicate or quadruplicate wells for each condition were used routinely.

\section{Immunofluorescence Imaging}

Following treatment and incubation of cells as required, the cells were washed with PBS $(\times 2)$ prior to fixation with paraformaldehyde $(4 \%, w / v)$ in PBS for 15 min followed by 
PBS washing $(\times 2)$. Cells were then permeabalized with Triton X-100 $(0.3 \%$, v/v) in PBS for $5 \mathrm{~min}$ at room temperature (RT), followed by blocking with bovine serum albumin (BSA; 3\%, w/v) in PBS at RT for $1 \mathrm{~h}$. Hoechst (1:2000) and phalloidin-TRITC (1:500) were added to the blocking buffer. Following washing, the cells were incubated with primary antibody diluted in BSA (3\%,w/v) in PBS and incubated overnight at $4{ }^{\circ} \mathrm{C}$. The cells were washed with PBS $(\times 3)$, followed by incubation with the appropriate secondary antibody conjugated to Alexa 488 or Alexa 594 (Invitrogen) for $1 \mathrm{~h}$ at RT. Images were captured using an inverted light microscope (Nikon, Eclipse TE-300).

\subsection{SDS-PAGE, Zymography, and WESTERN Blotting}

Protein solutions were quantified using the BCA (Pierce) protein assay or with a Nanodrop 8000 UV-Vis spectrophotometer and electrophoresed on gradient (5-20\%) or uniform concentration (12.5\%) acrylamide gels using standard conditions.

Zymography was performed using gradient acrylamide gels copolymerized with bovine gelatin (Sigma; 0.05-0.1\%, w/v). Non-reducing sample buffer was used to solubilize samples without heat denaturation. Gels were electrophoresed at constant current $(25 \mathrm{~mA} / \mathrm{gel})$. Following electrophoresis, the gels were washed for $1 \mathrm{~h}$ in Triton X-100 (2.5\%, v/v) with gentle shaking, to remove excess SDS, followed by static incubation for approximately 24 $\mathrm{h}\left(37^{\circ} \mathrm{C}\right)$ in $25 \mathrm{mM}$ Tris buffer ( $\left.\mathrm{pH} 7.2\right)$, supplemented with $5 \mathrm{mM} \mathrm{CaCl}$. Gels were then stained with Coomassie blue (R250) for at least $1 \mathrm{~h}$ followed by de-staining in methanol $(30 \%, \mathrm{v} / \mathrm{v})$ and acetic acid $(10 \%, \mathrm{v} / \mathrm{v})$. Zones of proteolysis were visualized as clear areas against a light or dark blue background, depending on the extent of destaining required.

\subsection{Western Blotting}

Proteins $(25-50 \mu \mathrm{g} /$ lane $)$ were transferred $(1 \mathrm{~mA} / \mathrm{cm} 2$ for $1 \mathrm{~h})$ to polyvinylidene difluoride membrane (Roth) using a semi-dry blotting apparatus (Atto). Blots were blocked with non-fat dry milk $(5 \%, \mathrm{w} / \mathrm{v})$ or BSA $(3 \%, \mathrm{w} / \mathrm{v})$, in PBS, followed by incubation with the appropriate primary antibody overnight at $4{ }^{\circ} \mathrm{C}$. Following washing with PBS containing Tween-20 (0.05\%, v/v), blots were incubated with secondary antibody for $1 \mathrm{~h}$ at RT, washed and developed using enhanced chemiluminescence. Densitometry of gels/blots was performed using Image J software $(\mathrm{NIH})$ with expression levels of proteins normalized to an appropriate loading control.

\subsection{LPS Purification}

The method for LPS isolation from F. nucleatum was performed essentially as described in Ref. [19] and the sliver staining protocol described in Ref. [20] was used to assess purity.

Primary antibodies. The following antibodies were used: Anti-ZEB-1 (Novus Biologicals, NBP1-88845 or NBP1-05987); Anti-E-cadherin (BD Transduction: 610182); Anti-PCNA (Novus Biologicals: NB500-106H); Anti-tubulin (Sigma: T6199); Anti-STAT-3 (Cell Signalling: D3Z2G); and Anti-p-STAT-3 (Cell Signalling: D3A7). 


\subsection{Determination of Cytokine/Chemokine Production}

The amount of IL-8 secreted by colonic cells in response to various treatments was determined by ELISA (R\&D Duoset) according to the manufacturer's instructions.

\section{5. $q P C R$}

Primers used for RT-PCR are shown in Table S1. All primers were predesigned KiCqStart SYBR Green RT-qPCR Primers (Sigma). cDNA was obtained using the SensiFAST cDNA Synthesis Kit (Bioline) according to the manufacturer's instructions. The quantity of extracted cDNA was evaluated using a Nanodrop 8000. The qPCR assay was performed using the sensiFAST SYBR No-ROX Kit (Bioline) as recommended. The following amplification conditions were used on the Illumina Eco RT-PCR System: (i) preamplification cycle for $15 \mathrm{~min}$ at $95^{\circ} \mathrm{C}, 40$ amplification cycles for $1 \mathrm{~min}$ at $95^{\circ} \mathrm{C}, 1 \mathrm{~min}$ at $55^{\circ} \mathrm{C}$ and $1 \mathrm{~min}$ at $72{ }^{\circ} \mathrm{C}$ (ii) end-amplification cycle for $15 \mathrm{~s}$ at $95{ }^{\circ} \mathrm{C}, 15 \mathrm{~s}$ at $55^{\circ} \mathrm{C}$,

TABLE S1. Primers used for RT-PCR

\begin{tabular}{|c|c|c|}
\hline Primer & Forward sequence & Reverse sequence \\
\hline GAPDH & ACAGTTGCCATGTAGACC & TTTTTGGTTGAGCACAGG \\
\hline IL-8 & GTTTTTGAAGAGGGCTGAG & TTTGCTTGAAGTTTCACTGG \\
\hline CXCL-1 & ATGCTGAACAGTGACAAATC & TCTTCTGTTCСTATAAGGGC \\
\hline TNF- $\alpha$ & AGGCAGTCAGATCATCTTC & TTATCTCTCAGCTCCACG \\
\hline IL-1 $\beta$ & CTAAACAGATGAAGTGCTCC & GGTCATTCTCCTGGAAGG \\
\hline IL-6 & GCAGAAAAAGGCAAAGAATC & CTACATTTGCCGAAGAGC \\
\hline CCL-20 & TATATTGTGCGTCTCCTCAG & GCTATGTCCAATTCCATTCC \\
\hline MMP-1 & AAAGGGAATAAGTACTGGGC & CAGTGTTTTCCTCAGAAAGAG \\
\hline MMP-2 & GTGATCTTGACCAGAATACC & GCCAATGATCCTGTATGTG \\
\hline MMP-9 & AAGGATGGGAAGTACTGG & GCCCAGAGAAGAAGAAAAG \\
\hline MMP-10 & AGCGGACAAATACTGGAG & GTGATGATCCACTGAAGAAG \\
\hline MMP-13 & AGGCTACAACTTGTTTCTTG & AGGTGTAGATAGGAAACATGAG \\
\hline BMP-1 & GATGTGAAAAAGGACTATGGC & AATCTCAAAGGACTGGAATG \\
\hline FN-1 & CCATAGCTGAGAAGTGTTTTG & CAAGTACAATCTACCATCATCC \\
\hline ITGA-5 & AAGCTTGGATTCTTCAAACG & TCCTTTTCAGTAGAATGAGGG \\
\hline $\mathrm{CDH}-1$ & CCGAGAGCTACACGTTC & TCTTCAAAATTCACTCTGCC \\
\hline $\mathrm{CDH}-2$ & ACATATGTGATGACCGTAAC & TTTTTCTCGATCAAGTCCAG \\
\hline Snal-1 & CTCTAATCCAGAGTTTACCTTC & GACAGAGTCCCAGATGAG \\
\hline Snal-2 & CAGTGATTATTTCCCCGTATC & CCCCAAAGATGAGGAGTATC \\
\hline Snal-3 & TCCTTCCTGGTGAAAACG & CACCATTGATTTCTCTCTGC \\
\hline ZEB-1 & AAAGATGATGAATGCGAGTC & TCCATTTTCATCATGACCAC \\
\hline TWIST-1 & CTAGATGTCATTGTTTCCAGAG & CCCTGTTTCTTTGAATTTGG \\
\hline Vimentin & GGAAACTAATCTGGATTCACTC & CATCTCTAGTTTCAACCGTC \\
\hline $\mathrm{NF}-\kappa \beta 1$ & GACAACTATGAGGTCTCTGG & ATCACTTCAATTGCTTCGG \\
\hline$N F-\kappa \beta 2$ & TGAAGATTTCTCGAATGGAC & ACCTCAATGTCATCTTTCTG \\
\hline SOCS-3 & CCTATTACATCTACTCCGGG & ACTTTCTCATAGGAGTCCAG \\
\hline SPHK-1 & TTCCTTGAACCATTATGCTG & GATACTTCTCACTCTCTAGGTC \\
\hline PTGS-2 & AAGCAGGCTAATACTGATAGG & TGTTGAAAAGTAGTTCTGGG \\
\hline Wnt-7 $\alpha$ & AAAGATCCTGGAGGAGAAC & TGATCTTCAGGAAGGTGG \\
\hline Wnt-7 $\beta$ & GCAGGAAGGTTCTAGAGG & GTTGTACTTCTCCTTCAGC \\
\hline Wnt-9 $\alpha$ & GGTGTGAAGGTGATCAAG & TGCCGTCTCATACTTGTG \\
\hline MYC & TGAGGAGGAACAAGAAGATG & ATCCAGACTCTGACCTTTTG \\
\hline
\end{tabular}


and $15 \mathrm{~s}$ at $95^{\circ} \mathrm{C}$. All reactions were run in duplicate or triplicate with non-template and reverse transcriptase controls and normalized to GAPDH expression. Ct values were obtained during the exponential amplification phase using EcoStudy software (Illumina) and exported into Microsoft Excel for further analysis.

\subsection{Statistical Analyses}

Significant differences were determined by either applying the Student's $t$-test or analysis of variance (ANOVA), where appropriate.

\section{Results}

\subsection{Isolation and Proteomic Analysis of F. nucleatum OMV}

OMV isolated from the supernatant of broth grown F. nucleatum were 20-200 nm in diameter and free from intact cells and/or cellular debris (Figure 1A). Preparations of OMV contained two types of vesicles, single membrane and bi-layered species. The latter type (outer-inner MV) are released by other bacteria and contain both the inner cytoplasmic and outer membrane proteins [21] and likely account for the presence of cytoplasmic components frequently observed associated with OMV.

Proteomic analysis of F. nucleatum OMV identified 367 proteins (Tables S2-S6) and the predicted subcellular distribution of the constituents, determined using pSortB, is shown in Figure 1B.

TABLE S2. Cytoplasmic proteins $(193,52.32 \%)$ identified in F. nucleatum OMV

\begin{tabular}{|c|c|c|c|c|}
\hline $\begin{array}{l}\text { Accession } \\
\text { number }\end{array}$ & $\begin{array}{l}\text { Protein } \\
\text { score }^{b}\end{array}$ & $\%$ Coverage $^{c}$ & $\begin{array}{l}\text { Number } \\
\text { of peptide } \\
\text { matches }^{d}\end{array}$ & Description \\
\hline gi|19704946 & 205 & 42.8 & 16 & 50 S ribosomal protein L15P \\
\hline gi|19705258 & 112 & 19.4 & 3 & Hypothetical Protein FN1956 \\
\hline gi|19703929 & 131 & 43.3 & 18 & $\begin{array}{l}\text { (3R)-hydroxymyristoyl-ACP } \\
\text { dehydratase }\end{array}$ \\
\hline gi|19705272 & 130 & 33.5 & 11 & 4-amino-4-deoxychorismate lyase \\
\hline gi|19705330 & 481 & 54.5 & 46 & $50 \mathrm{~S}$ ribosomal protein $\mathrm{L} 1$ \\
\hline gi|19705329 & 153 & 47.1 & 12 & 50 S ribosomal protein L10P \\
\hline gi|19704452 & 139 & 42.3 & 15 & 50 S ribosomal protein $\mathrm{L} 21 \mathrm{P}$ \\
\hline gi|19704636 & 102 & 25 & 23 & $\begin{array}{l}\text { ABC transporter ATP-binding } \\
\text { protein }\end{array}$ \\
\hline gi|19703509 & 946 & 69.4 & 45 & $\begin{array}{l}\text { Anhydro-N-acetylmuramyl- } \\
\text { tripeptide amidase }\end{array}$ \\
\hline gi|19703677 & 207 & 25.5 & 14 & $\begin{array}{l}\text { Aspartate/aromatic } \\
\text { aminotransferase }\end{array}$ \\
\hline gi|19703545 & 329 & 64.9 & 18 & $\begin{array}{l}\text { Biotin carboxyl carrier protein of } \\
\text { glutaconyl-COA decarboxylase }\end{array}$ \\
\hline
\end{tabular}




\begin{tabular}{|c|c|c|c|c|}
\hline gi|19704783 & 233 & 33.3 & 17 & Cell division protein FtsZ \\
\hline gi|19705415 & 124 & 16.6 & 15 & DNA gyrase subunit A \\
\hline gi|19703626 & 79 & 4.2 & 5 & DNA polymerase III subunit alpha \\
\hline gi|19704618 & 105 & 29.8 & 17 & $\begin{array}{l}\text { DNA-directed RNA polymerase } \\
\text { subunit alpha }\end{array}$ \\
\hline gi|19704887 & 3191 & 84.5 & 157 & Elongation factor $\mathrm{Tu}$ \\
\hline gi|19703700 & 156 & 31.8 & 13 & F0F1 ATP synthase subunit beta \\
\hline gi|19705372 & 175 & 14.7 & 9 & Formatetetrahydrofolate ligase \\
\hline gi|19703370 & 446 & 52.6 & 22 & Hypothetical protein FN0018 \\
\hline gi|19704123 & 100 & 58.3 & 13 & Hypothetical protein FN0788 \\
\hline gi|19704424 & 138 & 31 & 10 & Hypothetical protein FN1089 \\
\hline gi|19704860 & 249 & 61 & 23 & Hypothetical protein FN1528 \\
\hline gi|19704939 & 384 & 53.1 & 27 & Hypothetical protein FN1618 \\
\hline gi|19705040 & 1407 & 76.2 & 99 & Hypothetical protein FN1719 \\
\hline gi|19705282 & 131 & 26.2 & 12 & Hypothetical protein FN1986 \\
\hline gi|19705408 & 234 & 73.1 & 29 & Hypothetical protein FN2118 \\
\hline gi|19703633 & 76 & 34.9 & 8 & $\begin{array}{l}\text { Hypoxanthine-guanine } \\
\text { phosphoribosyltransferase }\end{array}$ \\
\hline gi|19704566 & 141 & 37 & 19 & $\begin{array}{l}\text { Inosine-5'-monophosphate } \\
\text { dehydrogenase }\end{array}$ \\
\hline gi|19705114 & 92 & 17.7 & 6 & Iron/zinc/copper-binding protein \\
\hline gi|19704871 & 155 & 19.1 & 5 & Iron-sulfur cluster-binding protein \\
\hline gi|19703419 & 84 & 10.3 & 10 & Isoleucyl-tRNA synthetase \\
\hline gi|19704504 & 94 & 18.6 & 7 & L-lactate dehydrogenase \\
\hline gi|19705000 & 121 & 31.4 & 11 & LPS biosynthesis protein $\mathrm{WbpG}$ \\
\hline gi|19704441 & 96 & 12.7 & 4 & L-serine dehydratase \\
\hline gi|19703801 & 106 & 22.5 & 15 & lysyl-tRNA synthetase \\
\hline gi|19703494 & 571 & 43.8 & 30 & $\begin{array}{l}\text { Malonyl-coa-[acyl-carrier-protein] } \\
\text { transacylase }\end{array}$ \\
\hline gi|19704917 & 189 & 30.8 & 16 & $\begin{array}{l}\text { Nitrogen fixation iron-sulphur } \\
\text { protein RNFC }\end{array}$ \\
\hline gi|19703769 & 85 & 13.7 & 4 & Orotate phosphoribosyltransferase \\
\hline gi|19704711 & 132 & 29.2 & 16 & Oxaloacetate decarboxylase \\
\hline gi|19705105 & 215 & 33.7 & 30 & Peptidyl-prolyl cis-trans isomerase \\
\hline gi|19705412 & 607 & 44 & 63 & $\begin{array}{l}\text { Phenylalanyl-tRNA synthetase beta } \\
\text { chain }\end{array}$ \\
\hline gi|19704051 & 94 & 15 & 7 & $\begin{array}{l}\text { Phophatidylinositol-4-phosphate } \\
\text { 5-kinase }\end{array}$ \\
\hline gi|19704507 & 1046 & 52.8 & 75 & Phosphate acetyltransferase \\
\hline gi|19703989 & 245 & 54 & 26 & Phosphoglycerate kinase \\
\hline gi|19704064 & 156 & 44.3 & 15 & Phosphoglycerate mutase \\
\hline gi|19704323 & 90 & 14.8 & 6 & $\begin{array}{l}\text { Phosphoribosylaminoimidazole- } \\
\text { succinocarboxamide synthase }\end{array}$ \\
\hline
\end{tabular}




\begin{tabular}{|c|c|c|c|c|}
\hline gi|492611374 & 355 & 48.5 & 30 & Phosphotransacetylase \\
\hline gi| 19705045 & 87 & 17 & 4 & Potassium uptake protein KtrA \\
\hline gi|19704305 & 107 & 32 & 8 & Precorrin-8X methylmutase \\
\hline gi|19705039 & 271 & 41.2 & 72 & Preprotein translocase subunit SecA \\
\hline gi|19704888 & 487 & 38.5 & 51 & Elongation factor $\mathrm{G}$ \\
\hline gi|19704622 & 102 & 22 & 2 & $\begin{array}{l}\text { Protein translation initiation factor } \\
1\end{array}$ \\
\hline gi|492614315 & 117 & 33.5 & 8 & PTS glucose transporter subunit IIA \\
\hline gi|19704250 & 254 & 57.3 & 32 & $\begin{array}{l}\text { PTS system, N-acetylglucosamine- } \\
\text { specific IIA component }\end{array}$ \\
\hline gi|19704795 & 98 & 36.4 & 9 & Pyridoxal biosynthesis lyase PdxS \\
\hline gi|19704505 & 689 & 27.9 & 59 & Pyruvate-flavodoxin oxidoreductase \\
\hline gi|19705288 & 86 & 16.8 & 7 & $\begin{array}{l}\text { Ribose-phosphate } \\
\text { pyrophosphokinase }\end{array}$ \\
\hline gi|19704944 & 125 & 12.6 & 4 & Ribosome recycling factor (RRF) \\
\hline gi|19704912 & 168 & 25.2 & 8 & RNFB-related protein \\
\hline gi|19704093 & 124 & 39.9 & 22 & $\begin{array}{l}\text { Rod shape-determining protein } \\
\text { MreB }\end{array}$ \\
\hline gi|19704013 & 320 & 40 & 18 & Ser/Thr protein kinase \\
\hline gi|19713538 & 150 & 32.3 & 14 & Seryl-tRNA synthetase \\
\hline gi|19703829 & 189 & 35 & 16 & Short chain dehydrogenase \\
\hline gi|19703796 & 257 & 60.2 & 23 & Sigma(54) modulation protein \\
\hline gi|19705007 & 434 & 40.2 & 34 & $\begin{array}{l}\text { Spore coat polysaccharide } \\
\text { biosynthesis protein spsF }\end{array}$ \\
\hline gi|19704339 & 81 & 22.3 & 6 & $\begin{array}{l}\text { TetR family transcriptional } \\
\text { regulator }\end{array}$ \\
\hline gi|19705322 & 243 & 30.3 & 14 & $\begin{array}{l}\text { Thiamine biosynthesis lipoprotein } \\
\text { apbE }\end{array}$ \\
\hline gi|19703445 & 230 & 69.9 & 12 & Thioredoxin FN0093 \\
\hline gi|19704743 & 179 & 21.5 & 5 & Threonine dehydratase \\
\hline gi|19703946 & 98 & 39.6 & 8 & Threonyl-tRNA synthetase \\
\hline gi| 19703640 & 240 & 40.8 & 11 & Transketolase \\
\hline gi|19705316 & 372 & 29.7 & 27 & Translation initiation factor IF-2 \\
\hline gi| 19703670 & 77 & 29.8 & 10 & Translation initiation factor IF-3 \\
\hline gi|19705269 & 164 & 21.9 & 7 & Translation initiation inhibitor \\
\hline gi|19704701 & 118 & 47 & 13 & Triosephosphate isomerase \\
\hline gi|19705044 & 143 & 25 & 18 & $\begin{array}{l}\text { tRNA uridine } \\
5 \text {-carboxymethylaminomethyl } \\
\text { modification enzyme GidA }\end{array}$ \\
\hline gi|19705248 & 94 & 17.2 & 9 & Tryptophanase \\
\hline gi|19705010 & 123 & 45.2 & 26 & $\begin{array}{l}\text { UDP-4-dehydro-6-deoxy-2- } \\
\text { acetamido-D-glucose 4-reductase }\end{array}$ \\
\hline gi|19703818 & 198 & 42.1 & 19 & Uracil phosphoribosyltransferase \\
\hline
\end{tabular}




\begin{tabular}{|c|c|c|c|}
\hline gi|19704943 & 78 & 31.8 & 12 \\
\hline gi|19704127 & 120 & 18.4 & 13 \\
\hline gi|19703623 & 94 & 17 & 5 \\
\hline gi|19704614 & 102 & 16.6 & 7 \\
\hline gi|19705172 & 98 & 28.7 & 7 \\
\hline gi|19703553 & 826 & 52.9 & 39 \\
\hline gi|19704868 & 163 & 24.2 & 12 \\
\hline gi|19704796 & 156 & 15.3 & 9 \\
\hline gi|19704772 & 100 & 21.3 & 7 \\
\hline gi|19704851 & 173 & 28.6 & 8 \\
\hline gi|19704840 & 120 & 43.6 & 26 \\
\hline gi|19704967 & 322 & 62.1 & 25 \\
\hline gi|19704724 & 276 & 59.8 & 16 \\
\hline gi|19704941 & 265 & 47.4 & 33 \\
\hline gi|19704960 & 234 & 52.1 & 22 \\
\hline gi|19704951 & 592 & 53.8 & 39 \\
\hline gi|19705086 & 291 & 24.2 & 38 \\
\hline gi|19704420 & 89 & 30.8 & 7 \\
\hline gi|19704956 & 506 & 50.8 & 24 \\
\hline gi|19703772 & 470 & 61.2 & 46 \\
\hline gi|19703668 & 323 & 40.5 & 21 \\
\hline gi|19704950 & 284 & 58.8 & 33 \\
\hline gi|19705133 & 151 & 37.6 & 13 \\
\hline gi|19703830 & 403 & 49.5 & 25 \\
\hline gi|19705279 & 146 & 27.7 & 8 \\
\hline gi|19703392 & 148 & 27.5 & 13 \\
\hline gi|19705161 & 812 & 65.4 & 46 \\
\hline gi|19703464 & 316 & 31.1 & 22 \\
\hline gi|19704151 & 163 & 66.4 & 17 \\
\hline gi|19705185 & 86 & 41.1 & 12 \\
\hline gi|19703822 & 224 & 41.4 & 20 \\
\hline gi|19705416 & 131 & 18.9 & 16 \\
\hline gi|19705326 & 109 & 6.8 & 9 \\
\hline
\end{tabular}

Uridylate kinase

Urocanate hydratase

Xaa-His dipeptidase

Zinc metallohydrolase

Zn-dependent alcohol

dehydrogenase and related

dehydrogenase

(R)-2-hydroxyglutaryl-CoA

dehydratase beta-subunit

(S)-2-hydroxy-acid oxidase chain D

1-deoxy-D-xylulose-5-phosphate

synthase

1-phosphofructokinase

23S rRNA methyltransferase

3,4-dihydroxy-2-butanone-4-

phosphate synthase

30 S ribosomal protein S10P

30 S ribosomal protein S16P

30 S ribosomal protein $\mathrm{S} 2$

$30 \mathrm{~S}$ ribosomal protein S3P

$30 \mathrm{~S}$ ribosomal protein $\mathrm{S} 8 \mathrm{P}$

4-hydroxy-3-methylbut-2-enyl

diphosphate reductase/

4-methyl-5(B-hydroxyethyl)-

thiazole monophosphate

biosynthesis enzyme

50S ribosomal protein L14P

50 S ribosomal protein L19

50 S ribosomal protein L20

50 S ribosomal protein L6

50 S ribosomal protein L9P

acetyl-CoA acetyltransferase

Alkyl hydroperoxide reductase C22 protein

Asparaginyl-tRNA synthetase

Butyrate-acetoacetate CoA-

transferase subunit $B$

Chaperone protein DnaK

Dehydrogenase

Dihydropteridine reductase

D-lactate dehydrogenase

DNA gyrase subunit B

DNA-directed RNA polymerase subunit beta' 


\begin{tabular}{|c|c|c|c|c|}
\hline gi|19704865 & 386 & 45.5 & 28 & $\begin{array}{l}\text { Electron transfer flavoprotein } \\
\text { subunit alpha }\end{array}$ \\
\hline gi| 19705083 & 370 & 45.6 & 25 & Enolase \\
\hline gi|19703607 & 1516 & 52.2 & 153 & Formate acetyltransferase \\
\hline gi|19703667 & 999 & 74.9 & 68 & Fructose-1,6-bisphosphate aldolase \\
\hline gi|19705008 & 151 & 40.4 & 16 & Gluconate 5-dehydrogenase \\
\hline gi|19703547 & 130 & 31.2 & 15 & $\begin{array}{l}\text { Glutaconate coa-transferase subunit } \\
\text { A }\end{array}$ \\
\hline gi|19704729 & 90 & 25 & 3 & Glutaminase \\
\hline gi|19704192 & 308 & 29.3 & 30 & Glycogen phosphorylase \\
\hline gi|19703422 & 125 & 37.3 & 57 & Glycyl-trna synthetase beta chain \\
\hline gi|19703383 & 102 & 21 & 5 & Hypothetical Protein FN0031 \\
\hline gi|19703454 & 243 & 55.7 & 12 & Hypothetical Protein FN0106 \\
\hline gi|19703674 & 124 & 16.7 & 6 & Hypothetical Protein FN0331 \\
\hline gi|19703891 & 165 & 39.3 & 7 & Hypothetical Protein FN0556 \\
\hline gi|19704023 & 246 & 41.8 & 9 & Hypothetical Protein FN0688 \\
\hline gi|19704155 & 223 & 35.9 & 23 & Mercuric Reductase \\
\hline gi|19704603 & 110 & 10.8 & 6 & Methionyl-trna synthetase \\
\hline gi|19704036 & 80 & 12.2 & 7 & Methyltransferase \\
\hline gi|496072988 & 191 & 27.6 & 21 & Molecular chaperone GroEL \\
\hline gi|19704011 & 189 & 64.4 & 7 & Molecular chaperone GroES \\
\hline gi|19704060 & 196 & 45.7 & 13 & $\begin{array}{l}\text { molybdopterin biosynthesis MoeB } \\
\text { protein }\end{array}$ \\
\hline gi|19705005 & 208 & 34.2 & 12 & $\mathrm{~N}$-acetylneuraminate synthase \\
\hline gi|19704414 & 96 & 27.1 & 12 & Neutrophil-activating protein A \\
\hline gi|19704889 & 236 & 78.8 & 25 & $30 \mathrm{~S}$ ribosomal protein $\mathrm{S} 7$ \\
\hline gi|19704355 & 149 & 50 & 19 & 3-hydroxybutyryl-coa dehydratase \\
\hline gi|19705331 & 661 & 63.1 & 38 & 50 S ribosomal protein $\mathrm{L} 11 \mathrm{P}$ \\
\hline gi|19703672 & 436 & 69.4 & 28 & 50 S ribosomal protein L13 \\
\hline gi|19704617 & 100 & 45.7 & 28 & 50 S ribosomal protein $\mathrm{L} 17 \mathrm{P}$ \\
\hline gi|19704961 & 155 & 39.6 & 11 & 50 S ribosomal protein $\mathrm{L} 22 \mathrm{P}$ \\
\hline gi|19704966 & 572 & 44.5 & 30 & $50 \mathrm{~S}$ ribosomal protein $\mathrm{L} 3$ \\
\hline gi|19704506 & 254 & 35.7 & 21 & Acetate kinase \\
\hline gi|19704638 & 337 & 44.3 & 17 & $\begin{array}{l}\text { Adenosylcobalamin-dependent diol } \\
\text { dehydratase gamma subunit }\end{array}$ \\
\hline gi|19704784 & 126 & 23 & 11 & Cell division protein $\mathrm{ftsa}$ \\
\hline gi|19705246 & 126 & 15.5 & 17 & ClpB protein \\
\hline gi|19704932 & 86 & 13.8 & 2 & Competence protein \\
\hline gi|19703410 & 243 & 45.1 & 33 & Cysteine desulfhydrase \\
\hline gi|19704555 & 486 & 40.8 & 36 & Cysteine synthase \\
\hline gi|19705146 & 78 & 36.1 & 12 & Dihydroxyacetone kinase \\
\hline
\end{tabular}




\begin{tabular}{|c|c|c|c|c|}
\hline gi|19703888 & 127 & 24.9 & 22 & D-serine dehydratase \\
\hline gi|161485655 & 576 & 60.3 & 40 & Elongation factor Ts \\
\hline gi|19703548 & 214 & 49.1 & 19 & $\begin{array}{l}\text { Glutaconate coa-transferase subunit } \\
\text { B }\end{array}$ \\
\hline gi|19703987 & 178 & 31.9 & 27 & $\begin{array}{l}\text { Glyceraldehyde 3-phosphate } \\
\text { dehydrogenase }\end{array}$ \\
\hline gi|19703666 & 102 & 21.3 & 12 & Heat shock protein 90 \\
\hline gi|19704397 & 90 & 23.5 & 8 & Hydrolase \\
\hline gi|19703661 & 380 & 70.9 & 32 & Hypothetical protein FN0316 \\
\hline gi|19703794 & 160 & 23.8 & 6 & Hypothetical protein FN0459 \\
\hline gi|19704181 & 470 & 56.2 & 40 & Hypothetical protein FN0846 \\
\hline gi|19704259 & 95 & 12.1 & 3 & Hypothetical protein FN0924 \\
\hline gi|19704948 & 197 & 51.8 & 22 & $30 \mathrm{~S}$ ribosomal protein S5P \\
\hline gi|19704965 & 368 & 38.3 & 31 & 50 S ribosomal protein $\mathrm{L} 4$ \\
\hline gi|19705162 & 864 & 66.8 & 60 & $\begin{array}{l}\text { Acetoacetate:butyrate/acetate } \\
\text { coenzyme A transferase }\end{array}$ \\
\hline gi|19704633 & 134 & 64 & 15 & Adenylate kinase \\
\hline gi|19703644 & 121 & 22 & 11 & Aspartyl-trna synthetase \\
\hline gi|19704715 & 99 & 12.6 & 6 & Citrate lyase beta chain \\
\hline gi|19703592 & 684 & 68.1 & 45 & Cytoplasmic protein \\
\hline gi|19703911 & 108 & 17.1 & 5 & $\begin{array}{l}\text { D-amino acid dehydrogenase large } \\
\text { subunit }\end{array}$ \\
\hline gi|19704284 & 127 & 8.4 & 11 & DNA helicase \\
\hline gi|19704055 & 106 & 23.5 & 7 & Elongation factor $\mathrm{P}$ \\
\hline gi|19703519 & 95 & 26.1 & 7 & $\begin{array}{l}\text { Enoyl-[acyl-carrier-protein] } \\
\text { reductase }\end{array}$ \\
\hline gi|19704074 & 99 & 32.1 & 8 & $\begin{array}{l}\text { Formiminotetrahydrofolate } \\
\text { cyclodeaminase }\end{array}$ \\
\hline gi|492612068 & 696 & 56.7 & 54 & Glutamate dehydrogenase \\
\hline gi|19704076 & 120 & 33.3 & 12 & Glutamate formiminotransferase \\
\hline gi|19705283 & 99 & 19.4 & 7 & $\begin{array}{l}\text { GntR family transcriptional } \\
\text { regulator }\end{array}$ \\
\hline gi|19704158 & 137 & 21.5 & 14 & GTP-binding protein hflX \\
\hline gi|19704816 & 168 & 26.5 & 7 & Hypothetical protein FN1484 \\
\hline gi|19703947 & 106 & 36.7 & 7 & Hypothetical protein FN0612 \\
\hline gi|19704311 & 114 & 23.6 & 8 & Hypothetical protein FN0976 \\
\hline gi|19704619 & 285 & 62.1 & 34 & $30 \mathrm{~S}$ ribosomal protein $\mathrm{S} 4$ \\
\hline gi|19704953 & 392 & 60.1 & 37 & 50 S ribosomal protein L5 \\
\hline gi|19704656 & 594 & 36.7 & 41 & $\begin{array}{l}\text { Acetoacetate metabolism regulatory } \\
\text { protein atoC }\end{array}$ \\
\hline gi|19704118 & 303 & 38.3 & 30 & Acyl-coa dehydrogenase \\
\hline gi|19705363 & 173 & 33.3 & 11 & Adenine phosphoribosyltransferase \\
\hline
\end{tabular}




\begin{tabular}{|c|c|c|c|c|}
\hline gi|19705019 & 253 & 30.9 & 17 & $\begin{array}{l}\text { dTDP-4-dehydrorhamnose } \\
\text { reductase }\end{array}$ \\
\hline gi|19704119 & 806 & 56.5 & 49 & $\begin{array}{l}\text { Electron transfer flavoprotein } \\
\text { subunit beta }\end{array}$ \\
\hline gi|19703787 & 271 & 29.2 & 24 & $\begin{array}{l}\text { Glucosamine--fructose-6- } \\
\text { phosphate aminotransferase } \\
\text { [isomerizing] }\end{array}$ \\
\hline gi|19704881 & 191 & 47.6 & 20 & Hypothetical protein FN1549 \\
\hline gi|19704963 & 281 & 43.5 & 19 & $50 \mathrm{~S}$ ribosomal protein $\mathrm{L} 2$ \\
\hline gi|19703702 & 132 & 22.8 & 14 & F0F1 ATP synthase subunit alpha \\
\hline gi|19703594 & 127 & 42 & 8 & Hypothetical protein FN0249 \\
\hline gi|19705178 & 190 & 54.5 & 9 & $\operatorname{Bis}\left(5^{\prime}\right.$-nucleosyl)-tetraphosphatase \\
\hline gi|19703549 & 585 & 35.6 & 50 & $\begin{array}{l}\text { Glutaconyl-coa decarboxylase A } \\
\text { subunit }\end{array}$ \\
\hline gi|19703914 & 2000 & 46.9 & 143 & Cytoplasmic protein \\
\hline
\end{tabular}

${ }^{a}$ Accession number: a unique identifier assigned to the protein by FASTA database.

bProtein score: the protein score is the sum of the highest ions score for each distinct sequence.

c\% Coverage: The percentage of all the amino acids in the protein sequence that were covered by identified peptides detected in the sample, It is calculated from the length and the set of peptides assigned to the protein.

${ }^{\mathrm{d}}$ Number of peptide matches: The number of distinct peptide sequences in the protein group.

TABLE S3. Cytoplasmic membrane proteins $(32,8.72 \%)$ identified in the proteome of $F$. nucleatum OMV

\begin{tabular}{|c|c|c|c|c|}
\hline $\begin{array}{l}\text { Accession } \\
\text { number }\end{array}$ & $\begin{array}{l}\text { Protein } \\
\text { score }\end{array}$ & $\%$ Coverage & $\begin{array}{l}\text { Number } \\
\text { of peptide } \\
\text { matches }\end{array}$ & Description \\
\hline gi|19704586 & 84 & 5.8 & 2 & High-affinity iron permease \\
\hline gi|19704003 & 149 & 39.1 & 16 & $\begin{array}{l}\text { High-affinity zinc uptake system } \\
\text { protein znua precursor }\end{array}$ \\
\hline gi|19703356 & 158 & 20.5 & 11 & Inner membrane protein \\
\hline gi|19703718 & 151 & 17.3 & 8 & $\begin{array}{l}\text { Iron } \mathrm{ABC} \text { transporter } \mathrm{ATP} \text {-binding } \\
\text { protein } \mathrm{sfuC}\end{array}$ \\
\hline gi|19704697 & 111 & 14.6 & 3 & $\begin{array}{l}\text { Peptide } \mathrm{ABC} \text { transporter ATP-binding } \\
\text { protein }\end{array}$ \\
\hline gi|19704540 & 404 & 46.8 & 36 & Protease FN1205 \\
\hline gi|19704606 & 121 & 13.3 & 14 & Protease IV FN1271 \\
\hline gi|19703684 & 130 & 7.7 & 3 & Transport protein FN0341 \\
\hline gi|19704462 & 230 & 20.5 & 15 & Hypothetical protein FN1127 \\
\hline gi|19705281 & 164 & 19.4 & 10 & Hypothetical protein FN1985 \\
\hline gi|19704202 & 78 & 20.2 & 21 & Long-chain-fatty-acid-Coa ligase \\
\hline gi|19705321 & 255 & 15.9 & 14 & $\begin{array}{l}\text { Membrane-bound proton- } \\
\text { translocating pyrophosphatase }\end{array}$ \\
\hline gi|19704863 & 116 & 17.6 & 6 & Negative regulator of murein hydrolase \\
\hline gi|19704034 & 78 & 14.1 & 5 & Protein translocase subunit SecD \\
\hline
\end{tabular}




\begin{tabular}{|c|c|c|c|c|}
\hline gi|19704670 & 138 & 40.4 & 9 & Protein translocase subunit YajC \\
\hline gi|492609716 & 119 & 12.4 & 9 & PTS fructose transporter subunit IIC \\
\hline gi|19704773 & 295 & 19.7 & 20 & $\begin{array}{l}\text { PTS system, fructose-specific IIABC } \\
\text { component }\end{array}$ \\
\hline gi|19705163 & 167 & 5.2 & 6 & Short-chain fatty acids transporter \\
\hline gi|19703712 & 82 & 39.5 & 15 & Signal peptidase I \\
\hline gi|19705203 & 119 & 20.3 & 12 & Sugar transport ATP-binding protein \\
\hline gi|19703496 & 293 & 35.8 & 17 & $\begin{array}{l}\text { 3-oxoacyl-[acyl-carrier-protein] } \\
\text { synthase }\end{array}$ \\
\hline gi|19704546 & 126 & 15.5 & 10 & Cell division protein FtsI \\
\hline gi|19703805 & 113 & 4.3 & 3 & Efflux pump component MtrF \\
\hline gi|19704501 & 151 & 21.6 & 14 & $\begin{array}{l}\text { Galactose/methyl galaxtoside } \\
\text { transporter ATP-binding protein }\end{array}$ \\
\hline gi|19703566 & 134 & 11 & 9 & Carbon starvation protein A \\
\hline gi|19704710 & 85 & 12.3 & 4 & Citrate-sodium symport \\
\hline gi|496295757 & 152 & 37 & 18 & Gtpase Der \\
\hline $\begin{array}{l}\text { gi|19704112 } \\
\text { gi|19704050 }\end{array}$ & $\begin{array}{l}280 \\
184\end{array}$ & $\begin{array}{l}26.7 \\
25.5\end{array}$ & $\begin{array}{l}26 \\
12\end{array}$ & $\begin{array}{l}\text { GTP-binding protein lepA } \\
\text { Hypothetical protein FN0715 }\end{array}$ \\
\hline gi|19703521 & 666 & 76.9 & 52 & Cell division inhibitor MinD \\
\hline gi|19703515 & 86 & 20.5 & 13 & GTP-binding protein EngA \\
\hline gi|19703726 & 86 & 10.1 & 5 & Hypothetical protein FN0384 \\
\hline
\end{tabular}

TABLE S4. Periplasmic proteVins $(15,4.09 \%)$ identified in the proteome of F. nucleatum OMV

\begin{tabular}{lllll}
\hline $\begin{array}{l}\text { Accession } \\
\text { number }\end{array}$ & $\begin{array}{l}\text { Protein } \\
\text { score }\end{array}$ & \% Coverage & $\begin{array}{l}\text { Number } \\
\text { of peptide } \\
\text { matches }\end{array}$ & Description \\
\hline gi|19704500 & 1261 & 68.9 & 73 & D-galactose-binding protein \\
gi|19704333 & 527 & 52 & 40 & Dipeptide-binding protein FN0998 \\
gi|19703738 & 3874 & 67.9 & 252 & Dipeptide-binding protein FN0396 \\
gi|19704855 & 380 & 37.5 & 35 & Dipeptide-binding protein FN1523 \\
gi|19704446 & 92 & 14.7 & 8 & Dipeptide-binding protein FN1111 \\
gi|19703717 & 1145 & 57.7 & 66 & Iron(III)-binding protein \\
gi|19704730 & 92 & 8.1 & 4 & Amino acid carrier protein AlsT \\
gi|19704522 & 91 & 16.3 & 4 & Amino acid-binding protein \\
gi|19705117 & 76 & 12.6 & 3 & Manganese-binding protein \\
gi|19704804 & 112 & 20.8 & 7 & N-acetylneuraminate-binding protein \\
gi|19704836 & 528 & 37 & 34 & Nickel-binding protein \\
gi|19704648 & 95 & 10.3 & 5 & Oligopeptide-binding protein oppa \\
& & & & FN1313
\end{tabular}




\begin{tabular}{lllll} 
gi|19704973 & 176 & 17.8 & 10 & $\begin{array}{l}\text { Oligopeptide-binding protein oppa } \\
\text { FN1652 }\end{array}$ \\
gi|19704470 & 91 & 37.9 & 20 & $\begin{array}{l}\text { Phosphonates-binding protein } \\
\text { gi|19703953 }\end{array}$ \\
\hline
\end{tabular}

TABLE S5. Outer membrane proteins $(39,10.62 \%)$ identified in the proteome of F. nucleatum OMV

\begin{tabular}{|c|c|c|c|c|}
\hline $\begin{array}{l}\text { Accession } \\
\text { number }\end{array}$ & $\begin{array}{l}\text { Protein } \\
\text { score }\end{array}$ & $\%$ Coverage & $\begin{array}{l}\text { Number } \\
\text { of peptide } \\
\text { matches }\end{array}$ & Description \\
\hline gi|19705267 & 628 & 42 & 39 & Hemin receptor \\
\hline gi|19704535 & 581 & 78 & 44 & Hypothetical protein FN1200 \\
\hline gi|19704858 & 8168 & 64.1 & 509 & Hypothetical protein FN1526 (RadD) \\
\hline gi|19704886 & 1739 & 35.4 & 119 & Hypothetical protein FN1554 \\
\hline gi|19705337 & 3966 & 56.2 & 177 & Hypothetical protein FN2047 \\
\hline gi|19703624 & 130 & 22.7 & 6 & Lipoprotein 1 \\
\hline gi|492606366 & 2510 & 59.2 & 138 & Membrane protein \\
\hline gi|495968818 & 1032 & 30.4 & 115 & Membrane protein \\
\hline gi|492611696 & 6201 & 52.3 & 327 & Membrane protein \\
\hline gi|492656580 & 678 & 26 & 48 & $\begin{array}{l}\text { Outer membrane autotransporter barrel } \\
\text { domain-containing protein }\end{array}$ \\
\hline gi|19703678 & 920 & 76.2 & 50 & Outer membrane porin F FN0335 \\
\hline gi|19703598 & 241 & 48.4 & 18 & Outer membrane protein FN0253 \\
\hline gi|19704600 & 1264 & 36.1 & 40 & Outer membrane protein FN1265 \\
\hline gi|19703736 & 495 & 53.3 & 51 & Outer membrane protein FN0394 \\
\hline gi|19705216 & 2099 & 58 & 234 & Outer membrane protein FN1911 \\
\hline gi|19704338 & 2548 & 76.2 & 117 & $\begin{array}{l}\text { Outer membrane protein } \mathrm{P} 1 \text { precursor } \\
\text { FN1003 }\end{array}$ \\
\hline gi|19704608 & 1054 & 67.1 & 62 & Outer membrane protein TolC \\
\hline gi|496078626 & 3270 & 24.4 & 276 & Outer membrane protein, partial \\
\hline gi|492609940 & 157 & 23.4 & 8 & Cell wall endopeptidase M23 \\
\hline gi|530296 & 21135 & 78.3 & 1456 & Porin (FomA) FN1859 \\
\hline gi| 19705025 & 114 & 17.9 & 13 & Serine protease FN1074 \\
\hline gi|19705252 & 521 & 30.9 & 41 & Serine protease FN1950 \\
\hline gi|19704758 & 5430 & 53.2 & 262 & Serine protease FN1426 \\
\hline gi|492596693 & 841 & 12.3 & 73 & Serine protease \\
\hline gi|19703893 & 776 & 45.4 & 38 & $\begin{array}{l}\text { TraT complement resistance protein } \\
\text { precursor }\end{array}$ \\
\hline gi|492611516 & 2806 & 45.1 & 174 & $\begin{array}{l}\text { Fusobacterium outer membrane protein, } \\
\text { partial }\end{array}$ \\
\hline gi|19703727 & 127 & 28.1 & 11 & Hypothetical protein FN0385 \\
\hline
\end{tabular}




\begin{tabular}{|c|c|c|c|c|}
\hline gi|19704200 & 639 & 71 & 54 & Hypothetical protein FN0865 \\
\hline gi|492609727 & 205 & & 22 & Fusobacterium outer membrane protein \\
\hline gi|496079010 & 1215 & 21 & 77 & $\begin{array}{l}\text { Fusobacterium outer membrane protein } \\
\text { family }\end{array}$ \\
\hline gi|19704402 & 366 & 60.8 & 24 & Hypothetical protein FN1067 \\
\hline gi|19704070 & 2032 & 35.3 & 71 & Cell surface protein FN0735 \\
\hline gi|492611840 & 1249 & 23.3 & 87 & $\begin{array}{l}\text { Fusobacterium outer membrane protein, } \\
\text { partial }\end{array}$ \\
\hline gi|19705141 & 4724 & 73.3 & 294 & Hypothetical protein FN1836 \\
\hline gi|19703800 & 1207 & 68.5 & 92 & Hypothetical protein FN0465 \\
\hline gi|19703945 & 937 & 49.8 & 121 & Hypothetical protein FN0610 \\
\hline gi|19703599 & 2814 & 45.6 & 173 & Hypothetical protein FN0254 \\
\hline
\end{tabular}

TABLE S6. Proteins of unknown subcellular location $(89,24.25 \%)$ identified in the proteome of F. nucleatum OMV

\begin{tabular}{|c|c|c|c|c|}
\hline $\begin{array}{l}\text { Accession } \\
\text { number }\end{array}$ & $\begin{array}{l}\text { Protein } \\
\text { score }\end{array}$ & $\%$ Coverage & $\begin{array}{l}\text { Number } \\
\text { of peptide } \\
\text { matches }\end{array}$ & Description \\
\hline gi|19704160 & 173 & 45.1 & 25 & Cytoplasmic protein \\
\hline gi|19703402 & 968 & 63.6 & 71 & $\begin{array}{l}\text { Fumarate reductase flavoprotein } \\
\text { subunit }\end{array}$ \\
\hline gi|492614404 & 4560 & 51.1 & 199 & $\begin{array}{l}\text { Fusobacterium outer membrane } \\
\text { protein, partial }\end{array}$ \\
\hline gi|19704587 & 270 & 49.6 & 18 & $34 \mathrm{kDa}$ membrane antigen precursor \\
\hline gi|19703581 & 184 & 40.7 & 14 & $\begin{array}{l}\mathrm{ABC} \text { transporter substrate-binding } \\
\text { protein }\end{array}$ \\
\hline gi|66268805 & 87 & 35.1 & 5 & Apoptosis inducing membrane protein \\
\hline gi|19704593 & 453 & 46.2 & 33 & C4-dicarboxylate-binding protein \\
\hline gi|19703520 & 122 & 18.1 & 6 & Cell division inhibitor $\operatorname{minC}$ \\
\hline gi|19703522 & 112 & 47.5 & 11 & Cell division inhibitor minE \\
\hline gi|19704831 & 3558 & 50.9 & 141 & Cell surface protein FN1499 \\
\hline gi|19704473 & 226 & 39.9 & 11 & Cytoplasmic protein FN1138 \\
\hline gi|19703554 & 235 & 36 & 17 & Cytoplasmic protein \\
\hline gi|19704109 & 396 & 66.5 & 27 & Cytoplasmic protein \\
\hline gi|19705232 & 299 & 32.7 & 45 & DEGV protein \\
\hline gi|19703807 & 205 & 19.8 & 19 & Flavodoxin flda \\
\hline gi|496296672 & 1342 & 21.4 & 92 & $\begin{array}{l}\text { Fusobacterium outer membrane protein } \\
\text { family, partial }\end{array}$ \\
\hline gi|492611534 & 2863 & 35.7 & 157 & $\begin{array}{l}\text { Fusobacterium outer membrane } \\
\text { protein, partial }\end{array}$ \\
\hline gi|19705213 & 587 & 41.6 & 33 & $\begin{array}{l}\text { Glycerophosphodiester } \\
\text { phosphodiesterase }\end{array}$ \\
\hline gi|19703378 & 117 & 32.9 & 5 & Hypothetical protein FN0026 \\
\hline
\end{tabular}




\begin{tabular}{|c|c|c|c|c|}
\hline gi|19703401 & 434 & 43.2 & 20 & Hypothetical protein FN0049 \\
\hline gi|19703593 & 1034 & 68.8 & 56 & Hypothetical protein FN0248 \\
\hline gi|19703609 & 1101 & 62 & 53 & Hypothetical protein FN0264 (Fad A) \\
\hline gi|19703625 & 268 & 27.2 & 15 & Hypothetical protein FN0280 \\
\hline gi|19703694 & 388 & 70.8 & 20 & Hypothetical protein FN0351 \\
\hline gi|19703713 & 206 & 23.9 & 12 & Hypothetical protein FN0371 \\
\hline gi|19703732 & 103 & 52.6 & 10 & Hypothetical protein FN0390 \\
\hline gi|19703749 & 917 & 69.5 & 54 & Hypothetical protein FN0407 \\
\hline gi|19703892 & 130 & 26.2 & 12 & Hypothetical protein FN0557 \\
\hline gi|19703936 & 106 & 50.4 & 15 & Hypothetical protein FN0601 \\
\hline gi|19703972 & 96 & 45.3 & 13 & Hypothetical protein FN0637 \\
\hline gi|19703990 & 141 & 50 & 12 & Hypothetical protein FN0655 \\
\hline gi|19704024 & 459 & 62.1 & 29 & Hypothetical protein FN0689 \\
\hline gi|19704053 & 170 & 14.7 & 5 & Hypothetical protein FN0718 \\
\hline gi|19704066 & 243 & 63.8 & 30 & Hypothetical protein FN0731 \\
\hline gi|19704156 & 693 & 45.1 & 71 & Hypothetical protein FN0821 \\
\hline gi|19704167 & 282 & 74 & 11 & Hypothetical protein FN0832 \\
\hline gi|19704240 & 254 & 65.3 & 24 & Hypothetical protein FN0905 \\
\hline gi|19704251 & 1971 & 62.4 & 111 & Hypothetical protein FN0916 \\
\hline gi|19704282 & 180 & 38.5 & 12 & Hypothetical protein FN0947 \\
\hline gi|19704329 & 101 & 33.6 & 9 & Hypothetical protein FN0994 \\
\hline gi|19704340 & 252 & 45.9 & 20 & Hypothetical protein FN1005 \\
\hline gi|19704352 & 240 & 61.4 & 34 & Hypothetical protein FN1017 \\
\hline gi|19704408 & 177 & 28 & 5 & Hypothetical protein FN1073 \\
\hline gi|19704413 & 189 & 45.3 & 13 & Hypothetical protein FN1078 \\
\hline gi|19704479 & 1240 & 67.1 & 100 & Hypothetical protein FN1144 \\
\hline gi|19704488 & 183 & 32.1 & 5 & Hypothetical protein FN1153 \\
\hline gi|19704548 & 253 & 33.3 & 16 & Hypothetical protein FN1213 \\
\hline gi|19704588 & 1803 & 75.9 & 64 & Hypothetical protein FN1253 \\
\hline gi|19704668 & 106 & 31.9 & 5 & Hypothetical protein FN1333 \\
\hline gi|19704859 & 711 & 51.9 & 33 & Hypothetical protein FN1527 (Fad I) \\
\hline gi|19704861 & 81 & 45.5 & 2 & Hypothetical protein FN1529 \\
\hline gi|19704892 & 129 & 25.1 & 5 & Hypothetical protein FN1560 \\
\hline gi|19704968 & 2984 & 38.8 & 106 & Hypothetical protein FN1647 \\
\hline gi|19705089 & 201 & 41.7 & 11 & Hypothetical protein FN1784 \\
\hline gi|19705090 & 146 & 24.8 & 5 & Hypothetical protein FN1785 \\
\hline gi|19705097 & 2107 & 73.6 & 74 & Hypothetical protein FN1792 \\
\hline gi|19705112 & 639 & 62.1 & 31 & Hypothetical protein FN1807 \\
\hline gi|19705130 & 313 & 51.7 & 21 & Hypothetical protein FN1825 \\
\hline
\end{tabular}




\begin{tabular}{|c|c|c|c|c|}
\hline gi|19705140 & 84 & 23.1 & 3 & Hypothetical protein FN1835 \\
\hline gi|19705157 & 172 & 40.5 & 11 & Hypothetical protein FN1852 \\
\hline gi|19705198 & 4248 & 51.1 & 207 & Hypothetical protein FN1893 \\
\hline gi|19705215 & 358 & 61.1 & 36 & Hypothetical protein FN1910 \\
\hline gi|19705244 & 92 & 24.8 & 9 & Hypothetical protein FN1939 \\
\hline gi|19705348 & 2281 & 37.2 & 119 & Hypothetical protein FN2058 \\
\hline gi|19705411 & 541 & 51.7 & 40 & Hypothetical protein FN2121 \\
\hline gi|523655036 & 1502 & 21 & 90 & Hypothetical protein, partial \\
\hline gi|19704460 & 170 & 51.9 & 14 & LemA protein \\
\hline gi|19705204 & 467 & 35.8 & 25 & Lipoprotein 2 \\
\hline gi|492614725 & 554 & 50.1 & 32 & Membrane protein \\
\hline gi|496075624 & 1770 & 22.8 & 114 & Membrane protein \\
\hline gi|492610276 & 937 & 20.4 & 69 & Membrane protein \\
\hline gi|496075749 & 4243 & 39.5 & 238 & Membrane protein \\
\hline gi|496078982 & 4413 & 38.1 & 248 & Membrane protein \\
\hline gi|496070514 & 1312 & 18.7 & 84 & Membrane protein \\
\hline gi|492586863 & 1129 & 12.1 & 71 & Membrane protein \\
\hline gi|492647631 & 287 & 4.2 & 23 & Membrane protein \\
\hline gi|492564676 & 2158 & 15 & 187 & Membrane protein \\
\hline gi|492614450 & 8468 & 41.6 & 522 & Membrane protein \\
\hline gi|495977401 & 2768 & 19.3 & 257 & Membrane protein \\
\hline gi|19704915 & 100 & 24.9 & 5 & Nitrogen fixation protein RNFG \\
\hline gi|19703860 & 756 & 39.7 & 66 & Penicillin-binding protein \\
\hline gi|19705393 & 2071 & 84.1 & 106 & RecAprotein \\
\hline gi|19704409 & 120 & 26.7 & 8 & Signal recognition particle receptor ftsy \\
\hline gi|492611783 & 556 & 46.5 & 64 & Stage II sporulation protein spoiid \\
\hline gi|19704458 & 113 & 36.9 & 6 & Thioredoxin-like protein FN1123 \\
\hline gi|492607145 & 206 & 27.2 & 15 & Von Willebrand factor A \\
\hline gi|19704354 & 314 & 24 & 11 & 3-hydroxybutyryl-coa dehydrogenase \\
\hline gi|492620353 & 801 & & 48 & $\begin{array}{l}\text { Galactoside ABC superfamily ATP } \\
\text { binding cassette transporter, binding } \\
\text { protein }\end{array}$ \\
\hline gi|19704016 & 92 & 32.4 & 14 & MarR family transcriptional regulator \\
\hline
\end{tabular}

Several proteases were identified in the OMV (Table S7). Gelatin zymography (Figure 1D) of the purified OMV and F. nucleatum shown in Figure 1C demonstrate abundant $\mathrm{OMV}$-associated protease activity. In the image shown, there is no evidence of protease activity in whole F. nucleatum, however, activity could be detected if the bacteria were first subjected to a salt wash (PBS) and subsequently with $\mathrm{KCl}(0.5 \mathrm{M})$ to extract and concentrate cell surface-associated protease activities (Figure 1E). Throughout this procedure, the 
A

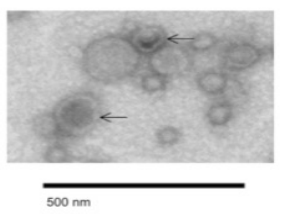

C

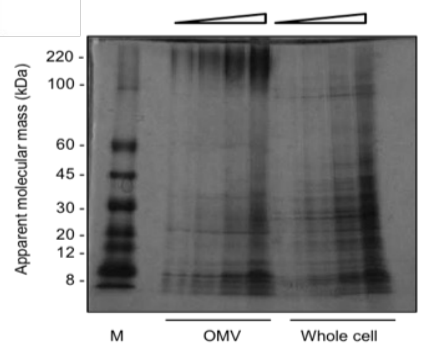

B

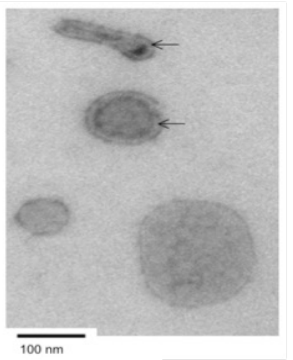

D

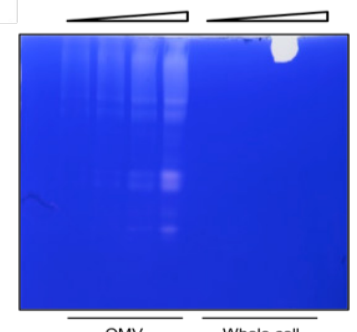

$\mathrm{E}$

FIGURE 1. F. nucleatum OMV proteome and proteolytic activities. A: TEM images of F. nucleatum OMV indicating the presence of bi-layered O-IMVs (arrows). Scale bar: 100 $\mathrm{nm}$ and $500 \mathrm{~nm}$. B: Summary of the predicted (pSortB) subcellular distribution of the 367 proteins identified by mass spectrometry C: Coomassie (G250) stained gradient (5-20\%) SDS-PAGE gel of increasing amounts of OMV and F. nucleatum. D: Gelatin (0.1\%) zymogram of the material shown in C. Zones of clearance indicate proteolysis. E: Gelatin $(0.05 \%)$ zymogram of subcellular fractionated proteolytic activity from F. nucleatum. S1: proteins recovered from a PBS-wash of whole cells. S2: $0.5 \mathrm{M} \mathrm{KCL}$ wash of PBS-treated cells. S3: cytoplasmic extract. S4: solubilized membrane extract. The apparent molecular mass markers are shown on the side of $\mathrm{C}$ (lane $\mathrm{M})$.

TABLE S7. Proteases identified in the F. nucleatum OMV proteome

\begin{tabular}{|c|c|c|c|c|c|}
\hline $\begin{array}{l}\text { Accession } \\
\text { number }\end{array}$ & $\begin{array}{l}\text { Protein } \\
\text { score }\end{array}$ & $\begin{array}{l}\% \\
\text { Coverage }\end{array}$ & $\begin{array}{l}\text { Number } \\
\text { of peptide } \\
\text { matches }\end{array}$ & Description & $\begin{array}{l}\text { Subcellular } \\
\text { location }\end{array}$ \\
\hline gi|19704540 & 404 & 46.8 & 36 & Protease FN1205 & Cytosol \\
\hline gi|19704606 & 121 & 13.3 & 14 & Protease IV FN1271 & Cytosol \\
\hline gi 19705025 & 114 & 17.9 & 13 & Serine protease FN1074 & Outer Membrane \\
\hline gi|19705252 & 521 & 30.9 & 41 & Serine protease FN1950 & Outer Membrane \\
\hline gi|19704758 & 5430 & 53.2 & 262 & Serine protease FN1426 & Outer Membrane \\
\hline gi| 492596693 & 841 & 12.3 & 73 & Serine protease & Outer Membrane \\
\hline gi| 19703623 & 94 & 17 & 5 & Xaa-His dipeptidase & Cytosol \\
\hline gi $\mid 49609940$ & 157 & 23.4 & 8 & $\begin{array}{l}\text { Cell wall endopeptidase } \\
\text { M23 }\end{array}$ & Outer Membrane \\
\hline gi|19703712 & 82 & 39.5 & 15 & Signal peptidase & Cytosol \\
\hline
\end{tabular}


bacteria remained intact as judged by microscopy with no evidence of cellular debris (Figure S1). Additional protease activities were detected in the cytoplasmic and membrane fractions (Figure 1E). The substrate spectrum of the admixture of proteases was evaluated by co-incubating OMV, whole F. nucleatum or ion-exchange (Mono Q) fractionated (IEX) protease activity with various substrates (gelatin, azocasein, azoalbumin, E-cadherin). The IEX protease activities demonstrated differential abilities to degrade the non-specific chromogenic substrates azoalbumin and azocasein, with azocasein being preferentially degraded by the majority of protease active fractions (not shown). The ability of the whole bacteria (Fnn) and OMV to degrade E-cadherin was assessed also with evidence of proteolysis of E-cadherin by both F. nucleatum and OMV (Figure 2A).

Given the ability of both OMV and intact bacteria to degrade the adherens junctional molecule E-cadherin we investigated if both could modulate the epithelial barrier function (TEER) of T84 and Caco 2 colonic cell monolayers. Both F. nucleatum and OMV reduced the TEER of Caco2 (Figure 2B) and T84 (Figure 2C) cells over time. The response of both cell lines to treatment with OMV and F. nucleatum differed, as indicated by the longer time to onset of the decrease in barrier integrity in Caco-2 compared with T84 cells.

\subsection{OMV Induce Pro-inflammatory Cytokine Secretion from Colonic Epithelial Cells}

Both OMV and whole F. nucleatum induced the expression of CXCL8 in a dose-dependent manner (Figure 3A and B) in SW480 cells and secretion of IL- 8 by SW480, SW620, and T84 colonic cells at 6 and 24 h post-treatment was confirmed by ELISA (Figure 3C). Similarly, IL- 8 secretion by SW 480 cells was induced by F. vincentii, F. polymorphum, and their OMV (Figure 3D) and OMV-induced IL-8 secretion by SW480 cells was sustained over $72 \mathrm{~h}$ (Figure S2). Infection-induced secretion of IL- 8 significantly reduced by the inhibitors SB203580 and PD98059 (Figure 3E), suggesting a role for the ERK mitogen-activated protein kinase (MAPK) and p38 MAPK pathways in OMV-mediated IL-8 expression.
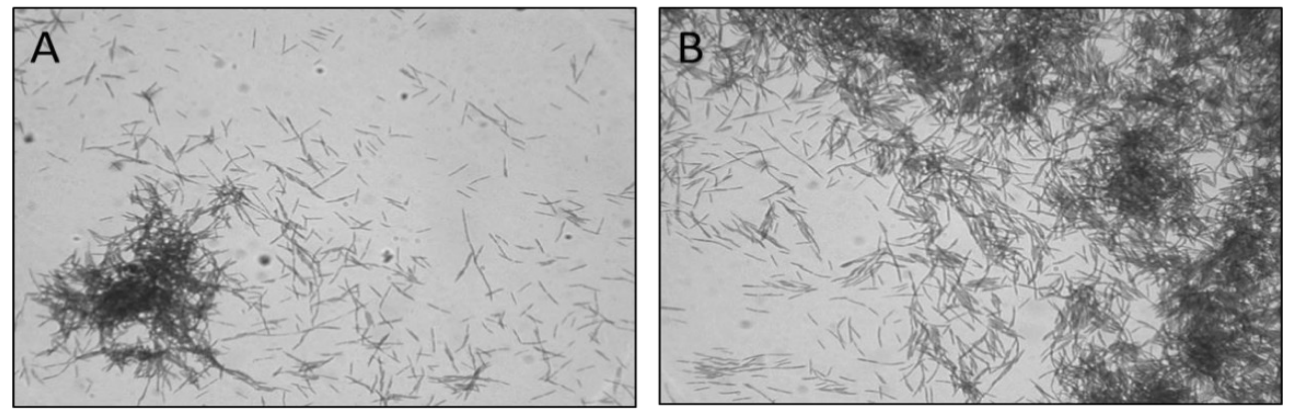

FIGURE S1. Gram stain of F. nucleatum recovered after extraction of protease activity by PBS and $\mathrm{KCl}$ wash. Panel A: F. nucleatum recovered after a PBS wash. Panel B: F. nucleatum recovered after a wash with PBS containing $0.5 \mathrm{M} \mathrm{KCl}$. Magnification: oil immersion, 100×. 
A

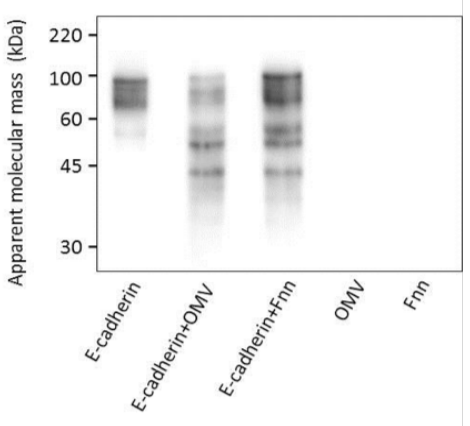

B
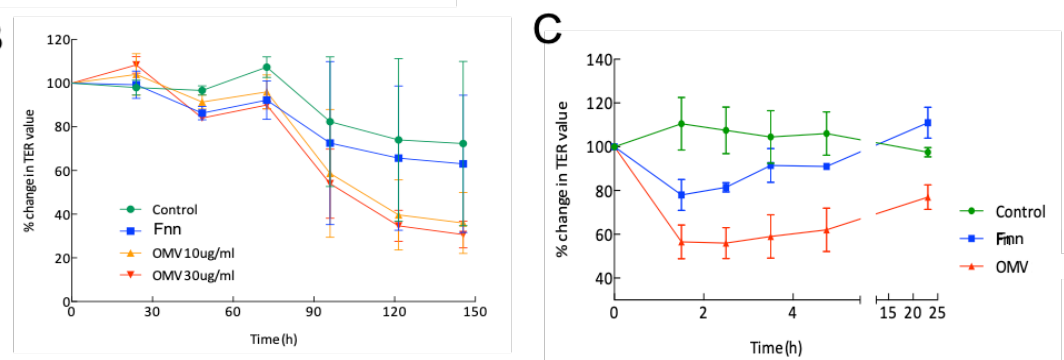

FIGURE 2. Effect of F. nucleatum and OMV on E-cadherin and the TEER of colonic cell monolayers. A: E-cadherin was co-incubated with OMV and F. nucleatum for $24 \mathrm{~h}$ prior to detecting products of E-cadherin degradation by Western blotting. B: Polarized and differentiated Caco2 and T84 cells (C) were treated with F. nucleatum and OMV once the cells reached a stable resistance (Time $=0$ ) and the TEER monitored at regular intervals over 148 (B) or $24 \mathrm{~h}(\mathrm{C})$ for Caco2 and T84 cells, respectively.

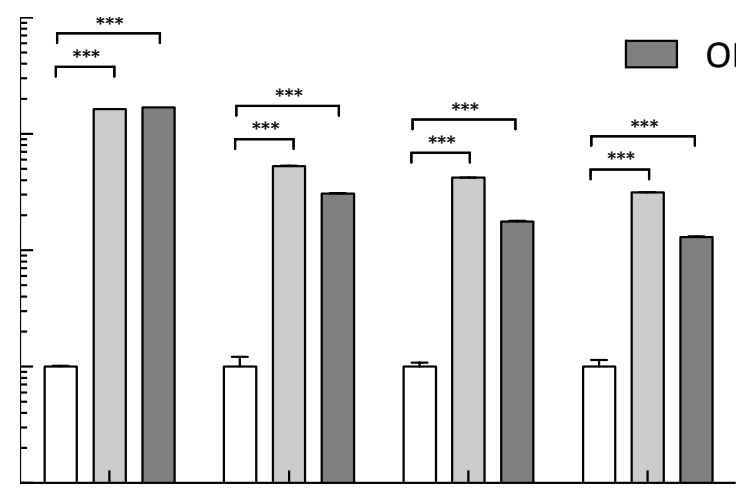

FIGURE S2. Time course of the effect of F. nucleatum and OMV in the induction of CXCL8 in SW-480 cells. SW-480 cells were treated with F. nucleatum (MOI 500:1) and OMV (30 $\mu \mathrm{g} /$ $\mathrm{ml}$ ) for the times indicated and relative expression was determined by RT-PCR. ${ }^{* *}=p<$ 0.001 . 
A

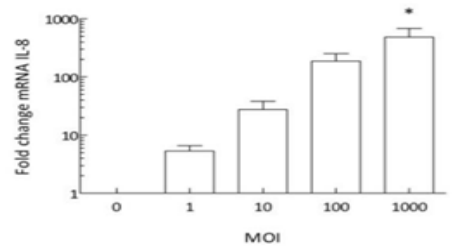

C

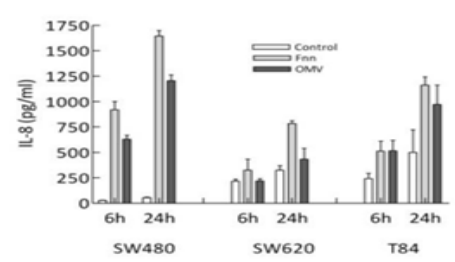

E

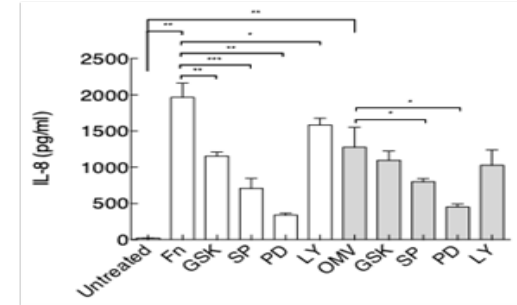

G

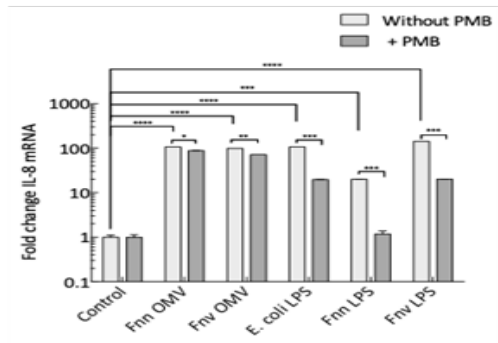

B

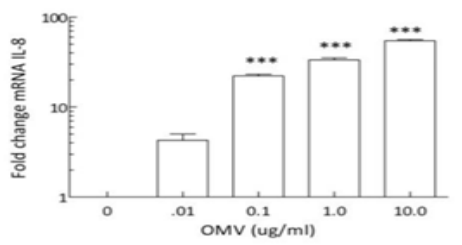

D

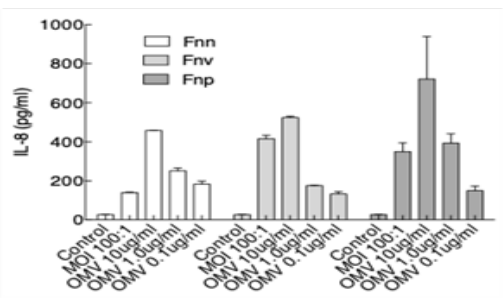

F

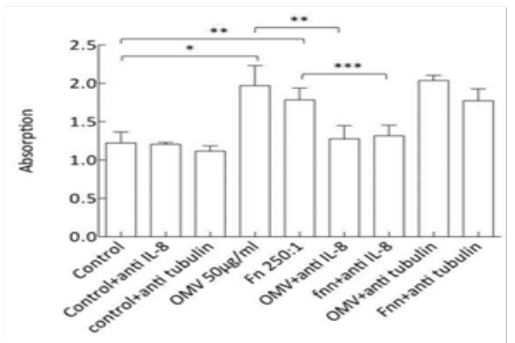

FIGURE 3. Effect of F. nucleatum and OMV on IL-8 gene and protein expression. Dosedependent effect of F. nucleatum (A) and OMV (B) on CXCL8 expression in SW480 cells ( $n=$ 3). C: Time course (6/24 h) of IL-8 secretion by SW480, SW620, and T-48 cells in the absence or presence of F. nucleatum (MOI 200:1) or OMV (5 $\mathrm{gg} / \mathrm{ml})$. Secreted IL-8 was detected by ELISA $(n=2)$. D: The effect of co-incubation ( $24 \mathrm{~h}$ ) of SW-480 cells with F. nucleatum (Fnn), F. vincentii (Fnv), and F. polymorphum (Fnp) (MOI: 100:1) and their OMV (0.1, 1, $10 \mu \mathrm{g} / \mathrm{ml}$ ) on IL-8 secretion. IL-8 secretion was measured by ELISA $(n=2)$. E: Effect of metabolic inhibitors on F. nucleatum- (Fn, white bars, MOI 150:1) and OMV (10 $\mu \mathrm{g} / \mathrm{ml})$-induced (grey bars) IL-8 secretion by SW-840 cells. The cells were treated with different inhibitors, GSK 690693

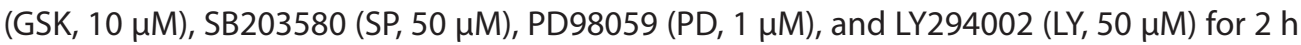
prior to the addition of bacteria or OMV and the incubation continued for an additional $4 \mathrm{~h}$. F: IL-8 acts as an autocrine growth signal; SW480 cells were seeded in a 96-well plate until 20-30\% confluent and then co-cultured alone or with F. nucleatum (MOI 250:1) or OMV (50 $\mu \mathrm{g} / \mathrm{ml}$ ) for $24 \mathrm{~h}$. Where indicated, the cells were also treated after $24 \mathrm{~h}$ with monoclonal anti 


\section{FIGURE 3. Continued}

IL-8 antibody $(0.24 \mu \mathrm{g} / \mathrm{ml})$ or monoclonal anti tubulin-a antibody $(0.24 \mu \mathrm{g} / \mathrm{ml})$, an isotype matched control, and the incubation continued for an additional $48 \mathrm{~h}$ after which time cell proliferation was assessed using Cell Titre One G: Contribution of F. nucleatum OMV LPS to IL-8 gene expression in SW-480 cells. The histogram illustrates the effect of polymyxin B (shaded bars) on CXCL8 expression in SW-480 cells treated with $10 \mathrm{ug} / \mathrm{ml}$ of F. nucleatum OMV, F. vincentii OMV, E. coli LPS, F. nucleatum LPS, and F. vincentii LPS for $4 \mathrm{~h}$. The results are represented as the mean $\pm \operatorname{SEM}(n=3){ }^{*}=p<0.05,{ }^{* *}=p<0.01,{ }^{* * *}=p<0.001$, and **** $=p<0.0001$.

Neither the PI3 kinase inhibitor LY294002 nor the Akt inhibitor GSK 690693 had a significant effect on IL-8 production by infected cells.

Both OMV- and F. nucleatum-induced IL-8 secreted by SW-480 cells appears to act in an autocrine-like manner to drive cell proliferation as this proliferative effect was significantly attenuated in the presence of a murine anti-human neutralizing IL- $8 \mathrm{mAb}$ whereas a matched isotype control $\mathrm{mAb}$ had no effect (Figure 3F). Interestingly, OMVassociated LPS only made a minor contribution to CXCL8 expression as demonstrated by the significant but minor effect of Polymyxin B on OMV-induced CXCL8 expression in SW-480 cells, unlike purified F. nucleatum LPS (Figure 3G) where Polymyxin B treatment reduced the expression to basal levels.

Both F. nucleatum and OMV induced expression of several other chemokines/ cytokines and transcription factors in vitro including CXCL1, CXCL5, CCL20, TNF- $\alpha$ and IL-6 (Figure 4A), NF-kB1/2 (Figure 4B), and components of the Wnt pathway (Wnt 7A, 7B, 9A) (Figure 4C). In addition, the relative expression levels of Myc, SOCS3, SPHK1 and PGTS2 were increased on exposure of SW-480 cells to both F. nucleatum and OMV (Figure 4D). All these genes exhibit increased expression in individuals infected with moderate to high levels of F. nucleatum [5]. Finally, both F. nucleatum and OMV induced transient phosphorylation of STAT3 in SW-480 cells with an observed peak at 10 min, decreasing to control levels by $60 \mathrm{~min}$ (Figure 4E).

\subsection{F. nucleatum and OMV Induce Morphological Changes and ZEB1 Gene and Protein Expression in Colonic Cells}

Both F. nucleatum and OMV induced proliferation of SW480 cells as determined by monitoring wound closure in scratch wound assays and by direct colorimetric measurements of cell proliferation (not shown). Co-incubation of SW480 and SW620 cells with F. nucleatum and OMV, respectively, induced morphological changes with the cobblestone appearance of untreated SW480 cells (Figure 5A) becoming progressively more fibroblast-like after exposure to $F$. nucleatum with a clear reduction in the number of intracellular contacts. Occasionally, similar changes were observed when SW480 cells were treated with OMV but consistently observed when SW620 cells were treated with either F. nucleatum or OMV (not shown). As such changes occur when cells undergo epithelial mesenchymal transition (EMT) we determined their effects on nuclear 
A

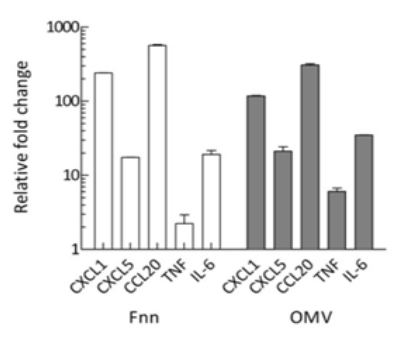

C

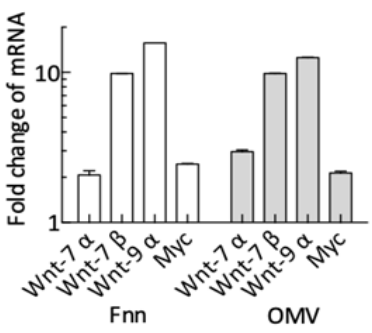

E
B

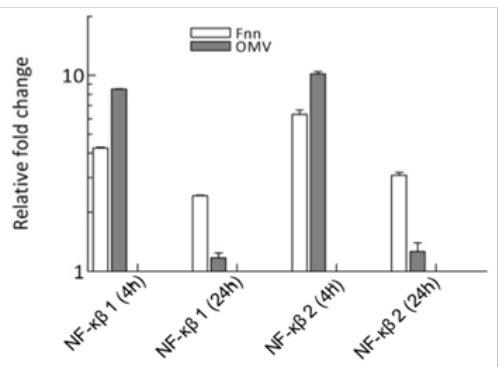

D

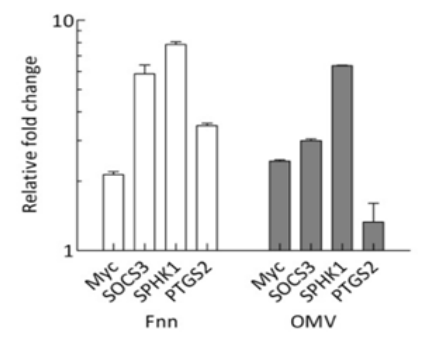

FIGURE 4. F. nucleatum and OMV induce pro-inflammatory transcription factors, cytokine/chermokines by colonic cells. A: F. nucleatum (MOI 100) and OMV $(10 \mu \mathrm{g} / \mathrm{ml})$ mediated induction of CXCL1, CXCL5, CCL20, TNF- $a$, IL-6 (A), NF-к $\beta 1 / 2$ h (B), Wnt-7 a, Wnt-7 $\beta$, Wnt-9 $a(C)$ and Myc, SOCS3, SPHK1, PGTS2 (D). All co-incubations were for $4 \mathrm{~h}$ except in $\mathrm{B}$, as indicated, and $n=2$. E: Western blot of STAT3 phosphorylation (Y705) induced by F. nucleatum (MOI 200) and OMV (30 $\mu \mathrm{g} / \mathrm{ml}$ )-treated (10-60 min) SW-480 cells. p-STAT-3 expression was normalized to total STAT-3 (histogram).

expression of ZEB1, a transcriptional repressor of CHD1 (E-cadherin), a hallmark of EMT. F. nucleatum stimulated ZEB1 nuclear expression in SW-480 cells as determined by immunofluorescence (Figure 5B) and qRT-PCR demonstrated a significant increase in $F$. nucleatum and OMV-induced ZEB1 expression (Figure 5C). Both the bacteria and their vesicles also stimulated ZEB1 accumulation in the nuclear fraction obtained from Caco2 (Figure 5D), SW-480, and SW-620 cells (not shown). 
A

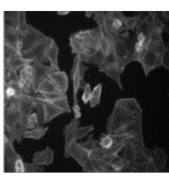

Contro

I

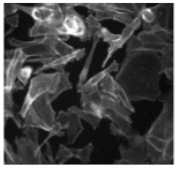

Fnn

B

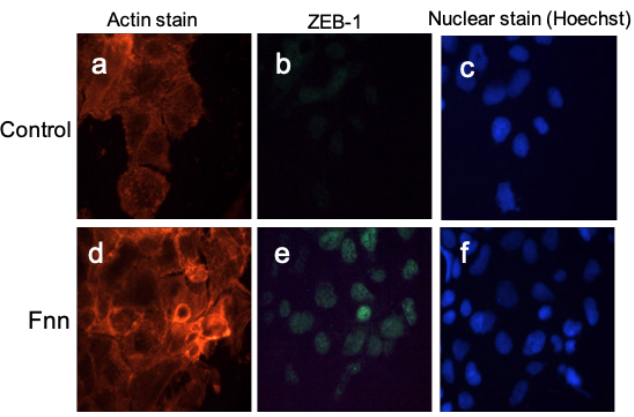

C

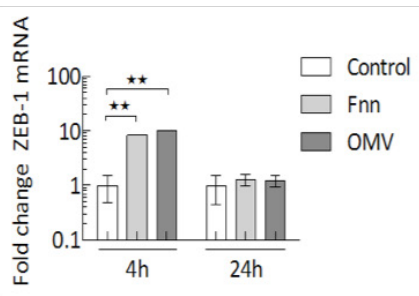

D

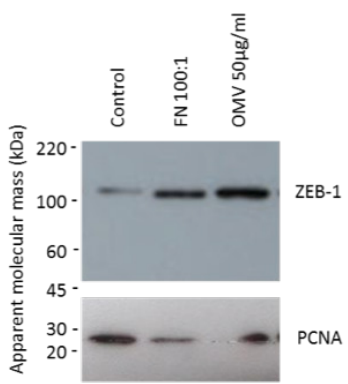

FIGURE 5. Effect of F. nucleatum and OMV on cellular morphology and ZEB1 expression in colonic cells. A: F. nucleatum (MOI 100) induce morphological changes in SW480 cells after co-incubation for $48 \mathrm{~h}$. Cells were fixed and stained with phalloidin (magnification $40 \times$ ). B: Immunofluorescence analysis of ZEB-1 nuclear expression in untreated (panel b) and F. nucleatum (MOI 100, 48 h) treated (panel e) SW480 cells. Also shown are the phalloidin (actin) (panels a, d) and Hoechst (panels c, f) stained cells (magnification 40X). C: ZEB1 mRNA expression in SW480 cells treated with F. nucleatum (Fnn, MOI 100) and OMV (10 $\mu \mathrm{g} /$ $\mathrm{ml}$ ) for 4/24 h. D: Western blot showing ZEB1 expression in nuclear extracts of Caco2 cells treated with F. nucleatum (MOI 100) and OMV $(50 \mu \mathrm{g} / \mathrm{ml})$ for $48 \mathrm{~h}$. PCNA was used as the nuclear fraction loading control (lower panel).

\subsection{F. nucleatum and OMV Reduce CDH1 Protein and Gene Expression and Promote an EMT-like Genotype in Colonic Cells}

Expression of CDH1 (transcript and protein) was down regulated in SW480 cells cocultured with F. nucleatum and OMV as determined by immunofluorescence (Figure 6A), Western blotting (Figure 6B), and qRT-PCR (Figure 6C). In addition, mRNA of the mesenchymal markers CDH2 (N-cadherin), VIM (vimentin), ITGA5 (Integrin subunit a 5, and FN1 (fibronectin) was upregulated (Figure 6D) as was SNAI1/2/3 (Snail family transcriptional repressors) and TWIST (Twist family BHLH transcription factor 1) (Figure 6E). Finally, both OMV and F. nucleatum modulated MMP 1, 2, 3, 9, 10, and 13 expression (Figure 6F). Taken together, these data indicate that F. nucleatum and OMV can contribute to the process of transition towards a mesenchymal phenotype in vitro. 
A

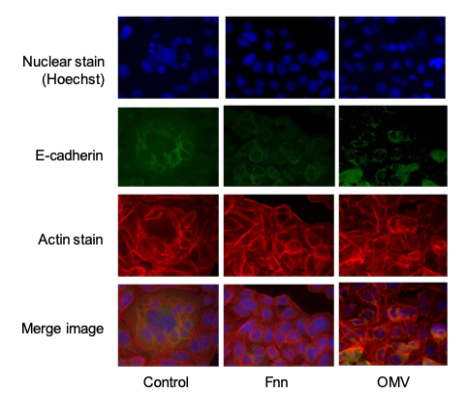

C

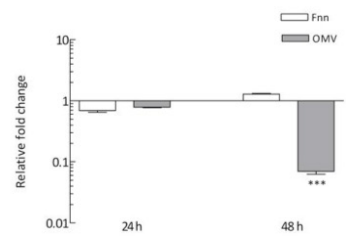

E

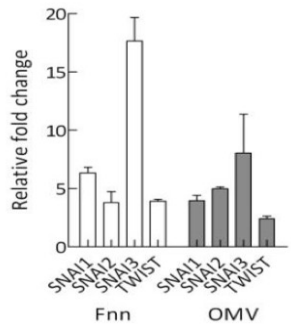

B

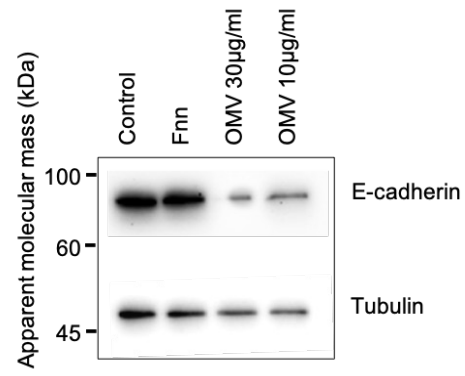

D

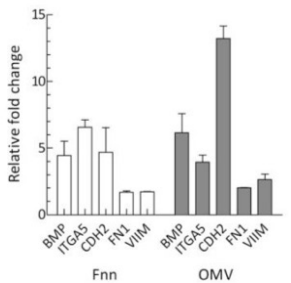

$\mathrm{F}$

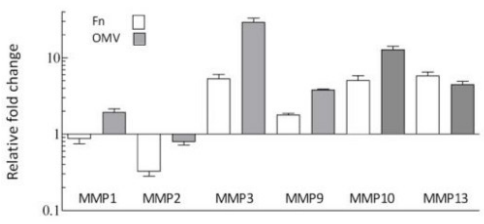

FIGURE 6. Effect of F. nucleatum and OMV on E-cadherin and EMT-marker expression. A: SW480 cells were treated with F. nucleatum (MOI 100:1) and OMV (50 $\mathrm{gg} / \mathrm{ml}$ ) for $24 \mathrm{~h}$ prior to detection of E-cadherin expression by immunofluorescence (green) (magnification 20X). B: Western blot showing reduced expression of E-cadherin in F. nucleatum (MOI 100) and OMV $(10,30 \mu \mathrm{g} / \mathrm{ml})$-treated cells. C: RT-PCR analysis of CDH1 expression in SW480 cells treated with F. nucleatum (MOI 200) and OMV $(20 \mu \mathrm{g} / \mathrm{ml})$ for 24-48 h $(\mathrm{n}=3 ; \mathrm{p}<0.001) \mathrm{D}$ : Expression of mesenchymal marker genes (BMP, ITGA5, CDH2, FN1, VIM) in SW480 cells induced by $\mathrm{F}$. nucleatum and OMV treatment ( $4 \mathrm{~h}, \mathrm{n}=2)$ ). E: Expression of SNAI3 and TWIST in SW480 cells co-cultured ( $4 \mathrm{~h}$ ) with F. nucleatum and OMV $(n=2)$. F: F. nucleatum and OMV modulate $\operatorname{MMP}(1,2,3,9,10$, and 13) expression in SW480 cells after co-culture for $4 \mathrm{~h}(\mathrm{n}=2)$.

\section{Discussion}

This study evaluated the ability of OMV from F. nucleatum to modulate cellular responses in colonic cells with respect to factors involved in inflammation and disease in the context of CRC. F. nucleatum is emerging as a pathogen of medical importance due to its significant 
association with CRC, and OMV from bacterial pathogens are known to promote disease progression. Thus, OMV were recovered from a sequenced (and invasive) strain of $F$. nucleatum (ATCC 25586) and the protein composition determined by mass spectrometry, resulting in the identification of 367 proteins. The presence of cytoplasmic proteins in the OMV preparation likely arises due to the presence of outer-inner membrane vesicles [21].

The F. nucleatum OMV proteome contains proteins known to be associated with pathogenesis [22] including the important adhesin FadA (FN0264) [6], and two others responsible for mediating multi-species co-aggregation, RadD (FN1526), and FomA (FN1859). RadD also mediates cell death in human lymphocytes [23]. In addition, active proteases were identified in the OMV which are capable of degrading host proteins.

Two other reports identified serine protease activity in F. nucleatum OMV reportedly capable of degrading IgA, fibronectin, and collagen [24-25]. Here we demonstrate the ability of OMV to degrade E-cadherin. Similar activity was observed with whole bacteria or with proteases partially purified from whole F. nucleatum, although the rates of degradation were slow when compared with other bacterial proteases with similar substrate specificity (e.g., HtrA from H. pylori [26]). Furthermore, OMV and F. nucleatum reduced the barrier integrity of colonic epithelial cell monolayers (T84 and Caco2) with OMV reducing the TEER more completely than intact F. nucleatum, suggesting that OMV can more efficiently transport proteolytic activity to the host cells. Such OMV-associated protease activity can damage host tissue [27-28] and disrupt intestinal barrier function and integrity [25]. Attempts were made to inhibit the F. nucleatum and OMV protease activity using a pan-protease inhibitor cocktail was unsuccessful as the inhibitors alone also modulated the barrier integrity. Additional attempts were made to pre-incubate OMV with the inhibitors followed by ultra-centrifugal washing prior to use but this approach led to significant loss of OMV.

Vesiculation is conserved biological process of gram-negative bacteria and has been shown to occur in vivo [29]. Analysis of OMV composition has provided evidence for selective enrichment of specific molecules, including proteases, in OMV from a variety of bacteria [30-35] and may also be the case in F. nucleatum OMV as judged by zymography. As OMV are not restricted to the niche occupied by the parental bacterium, they are a means for delivering effectors molecules in concentrated form to host cells [36-37] where they elicit potent inflammatory and other effects [33,38-41]. Vesicles are also involved in intercellular communication [42], horizontal transfer of virulence factors to eukaryotic cells and antibiotic resistance between bacteria [35,43]. In addition to protecting the bacteria from the host's innate immune response [44-45] they have been implicated in the pathogenesis of a broad range of infectious diseases, including periodontitis [33], gastritis [29,38], Crohn disease [40], salpingitis [46], meningitis [47-48], sepsis [49], and cardiovascular [50] and pulmonary disease [37].

In addition, OMVs are highly immunogenic and are considered to enhance pathogenicity by triggering the release of pro-inflammatory and immune regulatory cytokines, inducing neutrophil migration and recruitment and disrupting tight junctions in epithelial cell mono-layers [28,51]. Both F. nucleatum and OMV elicit potent proinflammatory responses in colonic epithelial cells as shown by increased transcript or protein abundance of CXCL1, CXCL5, CXCL8, CCL20, IL6, TFNa, NFkB1 (p105/p50), 
and NFkB2 (p100/p50). Several of these and other inflammatory cytokine/chemokines are dysregulated in adenomas [52] which negatively influences patient prognosis [53]. NF-kB can be activated by $>150$ stimuli and $>150$ genes are expressed on its activation [54-55]. Many of these genes encode proteins known to be essential for invasion and metastasis including adhesion molecules, MMPs, serine proteases, as well as pro-inflammatory cytokines and chemokines (e.g., TNFa, IL-1a, IL-6, CXCL8) which are associated with tumor development and progression in humans and mice [56-57]. Several studies have demonstrated the pro-inflammatory potential of F. nucleatum as evidenced by its ability to promote pro-inflammatory cytokine secretion from a variety of colonic/oral epithelial cells [58-60] and immune cells [61] and various Fusobacterial proteins can elicit this response including the major outer membrane FomA [62], the heat shock protein GroEL [63], and peptidoglycan [64], the former two being identified in the OMV proteome. Interestingly, although we have shown that F. nucleatumLPS induces CXCL8, the OMV-bound LPS appears to make little contribution to CXCL8 secretion by colonic cells suggesting that other constituents in the OMV are responsible for this activity.

Both F. nucleatum and OMV induced an EMT-like phenotype and genotype in colonic cells in vitro. In the presence of F. nucleatum and OMV, translocation of the transcriptional repressor ZEB1 to the nucleus was induced in colonic cells. Evidence of a mesenchymal genotype emerged upon treatment of SW-480 cells with F. nucleatum and OMV, as shown by the increased transcription of the mesenchymal markers CDH2 (N-cadherin), VIM (vimentin), ITGA5 (integrin subunit a5), FN1 (fibronectin), MMP3, MMP9, MMP10, and MMP13. Downregulation of E-cadherin is one of the essential initial events for EMT and is considered a hallmark of this process [65]. Both F. nucleatum and OMV also increased expression of the transcriptional repressors SNAI1, SNAI2, SNAI3, and TWIST with all implicated in carcinogenesis: for example, SNAI1 represses transcription of CDH1; SNAI2 induces the first phase of EMT, including desmosome dissociation, cell spreading, and initiation of cell separation [66-67]. N-cadherin is expressed by many tumor types and is associated with poor prognosis [68-69] and likewise with VIM [70-71] and FN1 [72-74]. Furthermore, both OMV and F. nucleatum activated STAT3 in colonic cells, a transcription factor known to be activated in various malignancies, including colon cancer [75]. Phosphorylated STAT3 regulates transcription of target genes (e.g., c-Myc) involved in promoting cell survival, proliferation, migration, and oncogenic transformation [76].

Among the E-cadherin repressors, ZEB1 is the most potent [77-78]. ZEB1 also represses regulators of epithelial differentiation, including cell polarity proteins, tight junctional proteins, desmosomes and gap junctional proteins [77] and has a role as a positive regulator of mesenchymal genes [79-80] and is implicated in aggressive cancers [81-82]. In colon cancer, ZEB1 was observed upregulated at the tumor-host interface and was accompanied by epithelial dedifferentiation and tumor cell invasion [77] in addition repressing the expression of laminin genes and this transient loss of a basement membrane component correlated with increased metastasis and poor patient survival [83].

EMT initiation (and ZEB1) is influenced by multiple signaling pathways including TGFb, RTKs, Wnt, IL-6/STAT3, NOTCH and TNF- $\alpha$ and control of expression by ZEB1 is cell and context dependent [79]. Microbe-induced EMT is now recognized to be elicited 
by several pathogens including $H$. pylori [84-85], K. pneumoniae [86], M. tuberculosis [87], P. gingivalis [88], C. rodentium [89], S. typhimurium [90], and P. aeruginosa [91].

\section{Conclusion}

These data demonstrate the potential for OMV from F. nucleatum to elicit phenotypic and genotypic modifications to colonic cells consistent with progression towards a more tumorigenic milieu. Further studies evaluating the pathogenic potential of these OMV in vivo are warranted.

\section{Acknowledgement}

The author thanks the Ministry of Higher Education in Saudi Arabia for granting a scholarship to continue the study in Ireland and also his research supervisor Dr. Henry Windle to complete this study.

\section{References}

1. Vogelstein B. Cancer genome landscapes. Science. 2013; 339(6127), 1546-1558.

2. Garrett WS. Cancer and the microbiota. Science. 2015; 348(6230), 80-86.

3. Wang T. Structural segregation of gut microbiota between colorectal cancer patients and healthy volunteers. The ISME Journal. 2012; 6(2), 320-329.

4. Warren RL. Co-occurrence of anaerobic bacteria in colorectal carcinomas. Microbiome. 2013; $1(1), 16$.

5. Kostic AD. Fusobacterium nucleatum potentiates intestinal tumorigenesis and modulates the tumor-immune microenvironment. Cell Host \& Microbe. 2013; 14(2), 207-215.

6. Rubinstein MR. Fusobacterium nucleatum promotes colorectal carcinogenesis by modulating E-cadherin/ $\beta$-catenin signaling via its FadA adhesin. Cell Host \& Microbe. 2013; 14(2), 195-206.

7. Castellarin M. Fusobacterium nucleatum infection is prevalent in human colorectal carcinoma. Genome Research. 2012; 22(2), 299-306.

8. Kostic AD. Genomic analysis identifies association of Fusobacterium with colorectal carcinoma. Genome Research. 2012; 22(2), 292-298.

9. Flanagan L. Fusobacterium nucleatum associates with stages of colorectal neoplasia development, colorectal cancer and disease outcome. European Journal of Clinical Microbiology \& Infectious Diseases. 2014; 33(8), 1381-1390.

10. Li YY. Association of Fusobacterium nucleatum infection with colorectal cancer in Chinese patients. World Journal of Gastroenterology. 2016; 22(11), 3227.

11. Wei Z. Could gut microbiota serve as prognostic biomarker associated with colorectal cancer patients' survival? A pilot study on relevant mechanism. Oncotarget. 2016; 7(29), 46158.

12. Gur C. Binding of the Fap2 protein of Fusobacterium nucleatum to human inhibitory receptor TIGIT protects tumors from immune cell attack. Immunity. 2015; 42(2), 344-355.

13. Suehiro Y. Highly sensitive stool DNA testing of Fusobacterium nucleatum as a marker for detection of colorectal tumors in a Japanese population. Annals of Clinical Biochemistry. 2017; 54(1), 86-91. 
14. Han YW. Identification and characterization of a novel adhesin unique to oral fusobacteria. Journal of Bacteriology. 2005; 187(15), 5330-5340.

15. Horiuchi A. Synergistic biofilm formation by Parvimonas micra and Fusobacterium nucleatum. Anaerobe. 2019, 102100.

16. Gendron R, Plamondon P, Grenier D. Binding of pro-matrix metalloproteinase 9 by Fusobacterium nucleatum subsp. nucleatum as a mechanism to promote the invasion of a reconstituted basement membrane. Infection and Immunity. 2004; 72(10), 6160-6163.

17. Leibovitz A. Classification of human colorectal adenocarcinoma cell lines. Cancer Research. 1976; 36(12), 4562-4569.

18. Mullaney E. Proteomic and functional characterization of the outer membrane vesicles from the gastric pathogen Helicobacter pylori. PROTEOMICS-Clinical Applications. 2009; 3(7), 785-796.

19. Eugene CY, Hackett M. Rapid isolation method for lipopolysaccharide and lipid A from gramnegative bacteria. Analyst. 2000; 125(4), 651-656.

20. Tsai CM, Frasch CE. A sensitive silver stain for detecting lipopolysaccharides in polyacrylamide gels. Analytical Biochemistry. 1982; 119(1), 115-119.

21. Pérez-Cruz C. Outer-inner membrane vesicles naturally secreted by gram-negative pathogenic bacteria. PLoS One. 2015; 10(1), e0116896.

22. Lee J, Kim OY, Gho YS. Proteomic profiling of Gram-negative bacterial outer membrane vesicles: current perspectives. PROTEOMICS-Clinical Applications. 2016; 10(9-10), 897-909.

23. Kaplan CW. Fusobacterium nucleatum outer membrane proteins Fap2 and RadD induce cell death in human lymphocytes. Infection and Immunity. 2010; 78(11), 4773-4778.

24. Bachrach G. Identification of a Fusobacterium nucleatum $65 \mathrm{kDa}$ serine protease. Oral Microbiology and Immunology. 2004; 19(3), 155-159.

25. Doron L. Identification and characterization of fusolisin, the Fusobacterium nucleatum autotransporter serine protease. PLoS One. 2014; 9(10), e111329.

26. Hoy B. Distinct roles of secreted HtrA proteases from gram-negative pathogens in cleaving the junctional protein and tumor suppressor E-cadherin. Journal of Biological Chemistry. 2012; 287(13), 10115-10120.

27. Nakao R. Effect of Porphyromonas gingivalis outer membrane vesicles on gingipain-mediated detachment of cultured oral epithelial cells and immune responses. Microbes and Infection. 2014; 16(1), 6-16.

28. Chi B, Qi M, Kuramitsu HK. Role of dentilisin in Treponema denticola epithelial cell layer penetration. Research in Microbiology. 2003; 154(9), 637-643.

29. Fiocca R. Release of Helicobacter pylori vacuolating cytotoxin by both a specific secretion pathway and budding of outer membrane vesicles. Uptake of released toxin and vesicles by gastric epithelium. The Journal of Pathology. 1999; 188(2), 220-226.

30. Kato S, Kowashi Y, Demuth DR. Outer membrane-like vesicles secreted by Actinobacillus actinomycetemcomitans are enriched in leukotoxin. Microbial Pathogenesis. 2002; 32(1), 1-13.

31. Elhenawy W, Debelyy MO, Feldman MF. Preferential packing of acidic glycosidases and proteases into Bacteroides outer membrane vesicles. MBio. 2014; 5(2), e00909- e00914.

32. Haurat MF. Selective sorting of cargo proteins into bacterial membrane vesicles. Journal of Biological Chemistry. 2011; 286(2), 1269-1276.

33. Veith PD. Porphyromonas gingivalis outer membrane vesicles exclusively contain outer membrane and periplasmic proteins and carry a cargo enriched with virulence factors. Journal of Proteome Research. 2014; 13(5), 2420-2432.

34. Bonnington K, Kuehn M. Protein selection and export via outer membrane vesicles. Biochimica et Biophysica Acta (BBA)-Molecular Cell Research. 2014; 1843(8), 1612-1619. 
35. Kulp A, Kuehn J. Biological functions and biogenesis of secreted bacterial outer membrane vesicles. Annual Review of Microbiology. 2010; 64, 163-184.

36. Manning AJ, Kuehn MJ. Functional advantages conferred by extracellular prokaryotic membrane vesicles. Journal of Molecular Microbiology and Biotechnology. 2013; 23(1-2), 131-141.

37. Bomberger JM. Long-distance delivery of bacterial virulence factors by Pseudomonas aeruginosa outer membrane vesicles. PLoS Pathogens. 2009; 5(4), e1000382.

38. Kaparakis M. Bacterial membrane vesicles deliver peptidoglycan to NOD1 in epithelial cells. Cellular Microbiology. 2010; 12(3), 372-385.

39. Irving AT. The immune receptor NOD1 and kinase RIP2 interact with bacterial peptidoglycan on early endosomes to promote autophagy and inflammatory signaling. Cell Host \& Microbe. 2014; 15(5), 623-635.

40. Rolhion N, Abnormally expressed ER stress response chaperone Gp96 in CD favours adherentinvasive Escherichia coli invasion. Gut. 2010; 59(10), 1355-1362.

41. Ellis TN, Kuehn MJ. Virulence and immunomodulatory roles of bacterial outer membrane vesicles. Microbiology and Molecular Biology Reviews. 2010; 74(1), 81-94.

42. Mashburn LM, Whiteley M. Membrane vesicles traffic signals and facilitate group activities in a prokaryote. Nature. 2005; 437(7057), 422.

43. Rompikuntal PK. Perinuclear localization of internalized outer membrane vesicles carrying active cytolethal distending toxin from Aggregatibacter actinomycetemcomitans. Infection and Immunity. 2012; 80(1), 31-42.

44. Grenier D, Belanger M. Protective effect of Porphyromonas gingivalis outer membrane vesicles against bactericidal activity of human serum. Infection and Immunity. 1991; 59(9), 3004-3008.

45. Manning AJ, Kuehn MJ. Contribution of bacterial outer membrane vesicles to innate bacterial defense. BMC Microbiology. 2011; 11(1), 258.

46. Gregg CR. Toxic activity of purified lipopolysaccharide of Neisseria gonorrhoeae for human fallopian tube mucosa. Journal of Infectious Diseases. 1981; 143(3), 432-439.

47. Stephens DS. Pili and outer membrane appendages on Neisseria meningitidis in the cerebrospinal fluid of an infant. Journal of Infectious Diseases. 1982; 146(4), 568.

48. Namork E, Brandtzaeg P. Fatal meningococcal septicaemia with "blebbing" meningococcus. The Lancet. 2002; 360(9347), 1741.

49. Shah B. Circulating bacterial membrane vesicles cause sepsis in rats. Shock. 2012; 37(6), 621-628.

50. Kuramitsu HK. Role for periodontal bacteria in cardiovascular diseases. Annals of Periodontology. 2001; 6(1), 41-47.

51. Sharpe SW, Kuehn MJ, Mason KM. Elicitation of epithelial cell-derived immune effectors by outer membrane vesicles of nontypeable Haemophilus influenzae. Infection and Immunity. 2011; 79(11), 4361-4369.

52. McLean MH. The inflammatory microenvironment in colorectal neoplasia. PLoS One. 2011; 6(1), e15366.

53. Galon J. Type, density, and location of immune cells within human colorectal tumors predict clinical outcome. Science. 2006; 313(5795), 1960-1964.

54. Pahl HL. Activators and target genes of Rel/NF- $\mathrm{kB}$ transcription factors. Oncogene. 1999; 18(49), 6853.

55. Bhatt D, Ghosh S. Regulation of the NF- $\kappa \mathrm{B}$-mediated transcription of inflammatory genes. Frontiers in Immunology. 2014; 5, 71.

56. Balkwill F, Mantovani A. Inflammation and cancer: back to Virchow? The Lancet. 2001; 357(9255), 539-545. 
57. Balkwill FR. The chemokine system and cancer. The Journal of Pathology. 2012; 226(2), 148-157.

58. Tang B. Fusobacterium nucleatum-induced impairment of autophagic flux enhances the expression of proinflammatory cytokines via ROS in Caco-2 cells. PLoS One. 2016; 11(11), e0165701.

59. Kang MS. Effects of methyl gallate and gallic acid on the production of inflammatory mediators interleukin- 6 and interleukin- 8 by oral epithelial cells stimulated with Fusobacterium nucleatum. The Journal of Microbiology. 2009; 47(6), 760-767.

60. Stathopoulou PG. Epithelial cell pro-inflammatory cytokine response differs across dental plaque bacterial species. Journal of Clinical Periodontology. 2010; 37(1), 24-29.

61. Kurgan Ş. Strain-specific impact of Fusobacterium nucleatum on neutrophil function. Journal of Periodontology. 2017; 88(4), 380-389.

62. Toussi DN, Liu X, Massari P. The FomA porin from Fusobacterium nucleatum is a toll-like receptor 2 agonist with immune adjuvant activity. Clinical and Vaccine Immunology. 2012; 19(7), 1093-1101.

63. Lee HR. Fusobacterium nucleatum GroEL induces risk factors of atherosclerosis in human microvascular endothelial cells and ApoE-/- mice. Molecular Oral Microbiology. 2012; 27(2), 109-123.

64. Okugawa T. NOD1 and NOD2 mediate sensing of periodontal pathogens. Journal of Dental Research. 2010; 89(2), 186-191.

65. Huber MA, Kraut N, Beug H. Molecular requirements for epithelial-mesenchymal transition during tumor progression. Current Opinion in Cell Biology. 2005; 17(5), 548-558.

66. Peinado H. Snail and E47 repressors of E-cadherin induce distinct invasive and angiogenic properties in vivo. Journal of Cell Science. 2004; 117(13), 2827-2839.

67. De Craene B. The transcription factor snail induces tumor cell invasion through modulation of the epithelial cell differentiation program. Cancer Research. 2005; 65(14), 6237-6244.

68. Blaschuk OW. N-cadherin antagonists as oncology therapeutics. Philosophical Transactions of the Royal Society B: Biological Sciences. 2015; 370(1661), 20140039.

69. Ye Z. Expression of IncRNA-CCAT1, E-cadherin and N-cadherin in colorectal cancer and its clinical significance. International Journal of Clinical and Experimental Medicine. 2015; 8(3), 3707.

70. Satelli A, Li S. Vimentin in cancer and its potential as a molecular target for cancer therapy. Cellular and Molecular Life Sciences. 2011; 68(18), 3033-3046.

71. Ivaska J. Vimentin: central hub in EMT induction? Small GTPases. 2011; 2(1), 1436-1448.

72. Bates RC, Mercurio A. The epithelial-mesenchymal transition (EMT) and colorectal cancer progression. Cancer Biology \& Therapy. 2005; 4(4), 371-376.

73. Cantor D. Overexpression of $\alpha v \beta 6$ integrin alters the colorectal cancer cell proteome in favor of elevated proliferation and a switching in cellular adhesion that increases invasion. Journal of Proteome Research. 2013; 12(6), 2477-2490.

74. Takamura M. Reduced expression of liver-intestine cadherin is associated with progression and lymph node metastasis of human colorectal carcinoma. Cancer Letters. 2004; 212(2), 253-259.

75. Zhang G, Yang W, Chen Z. Upregulated STAT3 and RhoA signaling in colorectal cancer (CRC) regulate the invasion and migration of CRC cells. European Review for Medical and Pharmacological Sciences. 2016; 20(10), 2028-2037.

76. Yu H. Revisiting STAT3 signalling in cancer: new and unexpected biological functions. Nature Reviews Cancer. 2014, 14(11), 736.

77. Aigner K. The transcription factor ZEB1 ( $\delta \mathrm{EF} 1)$ promotes tumour cell dedifferentiation by repressing master regulators of epithelial polarity. Oncogene. 2007; 26(49), 6979. 
78. Takeyama Y. Knockdown of ZEB1, a master epithelial-to-mesenchymal transition (EMT) gene, suppresses anchorage-independent cell growth of lung cancer cells. Cancer Letters. 2010; 296(2), 216-224.

79. Vandewalle C, Van Roy F, Berx G. The role of the ZEB family of transcription factors in development and disease. Cellular and molecular life sciences. 2009, 66 (5), pp. 773-787.

80. Lamouille S, Xu J, Derynck R. Molecular mechanisms of epithelial-mesenchymal transition. Nature Reviews Molecular Cell Biology. 2014; 15(3), 178.

81. Sánchez-Tilló E. EMT-activating transcription factors in cancer: beyond EMT and tumor invasiveness. Cellular and Molecular Life Sciences. 2012; 69(20), 3429-3456.

82. Spoelstra NS. The transcription factor ZEB1 is aberrantly expressed in aggressive uterine cancers. Cancer Research. 2006; 66(7), 3893-3902.

83. Spaderna S. A transient, EMT-linked loss of basement membranes indicates metastasis and poor survival in colorectal cancer. Gastroenterology. 2006; 131(3), 830-840.

84. Choi YJ. Helicobacter pylori-induced epithelial-mesenchymal transition, a potential role of gastric cancer initiation and an emergence of stem cells. Carcinogenesis. 2015; 36(5), 553-563.

85. Sougleri IS. Helicobacter pylori CagA protein induces factors involved in the epithelial to mesenchymal transition (EMT) in infected gastric epithelial cells in an EPIYA-phosphorylationdependent manner. The FEBS Journal. 2016; 283(2), 206-220.

86. Leone L. Klebsiella pneumoniae is able to trigger epithelial-mesenchymal transition process in cultured airway epithelial cells. PLoS One. 2016; 11(1), e0146365.

87. Gupta PK. Mycobacterium tuberculosis H37Rv infected THP-1 cells induce epithelial mesenchymal transition (EMT) in lung adenocarcinoma epithelial cell line (A549). Cellular Immunology. 2016; 300, 33-40.

88. Sztukowska MN. Porphyromonas gingivalis initiates a mesenchymal-like transition through ZEB1 in gingival epithelial cells. Cellular Microbiology. 2016; 18(6), 844-858.

89. Chandrakesan A. Utility of a bacterial infection model to study epithelial-mesenchymal transition, mesenchymal-epithelial transition or tumorigenesis. Oncogene. 2014; 33(20), 2639.

90. Tahoun A. Salmonella transforms follicle-associated epithelial cells into M cells to promote intestinal invasion. Cell Host \& Microbe. 2012; 12(5), 645-656.

91. Borthwick L. Pseudomonas aeruginosa accentuates epithelial-to-mesenchymal transition in the airway. European Respiratory Journal. 2011; 37(5), 1237-1247. 